University of Wollongong

Research Online

Australian Institute for Innovative Materials -

Papers

Australian Institute for Innovative Materials

$1-1-2019$

\title{
Sulfated polysaccharide-based scaffolds for orthopaedic tissue engineering
}

Jeremy Dinoro

University of Wollongong, jdn388@uowmail.edu.au

Malachy Maher

University of Wollongong, mkm290@uowmail.edu.au

Sepehr Talebian

University of Wollongong, st432@uowmail.edu.au

Mahboubeh Jafarkhani

Technical University of Denmark

Mehdi Mehrali

Technical University of Denmark

See next page for additional authors

Follow this and additional works at: https://ro.uow.edu.au/aiimpapers

Part of the Engineering Commons, and the Physical Sciences and Mathematics Commons

Research Online is the open access institutional repository for the University of Wollongong. For further information contact the UOW Library: research-pubs@uow.edu.au 


\title{
Sulfated polysaccharide-based scaffolds for orthopaedic tissue engineering
}

\author{
Abstract \\ Given their native-like biological properties, high growth factor retention capacity and porous nature, \\ sulfated-polysaccharide-based scaffolds hold great promise for a number of tissue engineering \\ applications. Specifically, as they mimic important properties of tissues such as bone and cartilage they \\ are ideal for orthopaedic tissue engineering. Their biomimicry properties encompass important cell- \\ binding motifs, native-like mechanical properties, designated sites for bone mineralisation and strong \\ growth factor binding and signaling capacity. Even so, scientists in the field have just recently begun to \\ utilise them as building blocks for tissue engineering scaffolds. Most of these efforts have so far been \\ directed towards in vitro studies, and for these reasons the clinical gap is still substantial. With this review \\ paper, we have tried to highlight some of the important chemical, physical and biological features of \\ sulfated-polysaccharides in relation to their chondrogenic and osteogenic inducing capacity. Additionally, \\ their usage in various in vivo model systems is discussed. The clinical studies reviewed herein paint a \\ promising picture heralding a brave new world for orthopaedic tissue engineering. \\ Disciplines \\ Engineering | Physical Sciences and Mathematics

\section{Publication Details} \\ Dinoro, J., Maher, M., Talebian, S., Jafarkhani, M., Mehrali, M., Orive, G., Foroughi, J., Lord, M. S. \& \\ Dolatshahi-Pirouz, A. (2019). Sulfated polysaccharide-based scaffolds for orthopaedic tissue engineering. \\ Biomaterials, 214 119214-1-119214-21.

\section{Authors} \\ Jeremy Dinoro, Malachy Maher, Sepehr Talebian, Mahboubeh Jafarkhani, Mehdi Mehrali, Gorka Orive, \\ Javad Foroughi, Megan S. Lord, and Alireza Dolatshahi-Pirouz
}




\section{Sulfated polysaccharide-based scaffolds for orthopaedic tissue engineering}

2 Authors: Jeremy Dinoro*1, Malachy Maher*1, Sepehr Talebian ${ }^{1,2}$, Mahboubeh Jarfarkhani ${ }^{3}$, Mehdi Mehrali

3 Gorka Orive ${ }^{4,5,6,7}$, Javad Foroughi ${ }^{1,2}$, Megan S. Lord ${ }^{8}$, Alireza Dolatshahi-Pirouz ${ }^{3,9}$

$4{ }^{1}$ Intelligent Polymer Research Institute ARC Centre of Excellence for Electromaterials Science AIIM Facility

5 University of Wollongong

$6{ }^{2}$ Illawarra Health and Medical Research Institute, University of Wollongong, Wollongong, NSW 2522, Australia

73 Technical University of Denmark, DTU Nanotech, Center for Intestinal Absorption and Transport of 8 Biopharmaceuticals, $2800 \mathrm{Kgs}$, Denmark.

$9{ }^{4}$ NanoBioCel Group, Laboratory of Pharmaceutics, School of Pharmacy, University of the Basque Country 10 UPV/EHU, Paseo de la Universidad 7, Vitoria-Gasteiz 01006, Spain.

$11{ }^{5}$ Biomedical Research Networking Centre in Bioengineering, Biomaterials and Nanomedicine (CIBER-BBN). 12 Vitoria-Gasteiz, Spain.

$13{ }^{6}$ University Institute for Regenerative Medicine and Oral Implantology - UIRMI (UPV/EHU-Fundación Eduardo 14 Anitua), Vitoria, Spain; BTI Biotechnology Institute, Vitoria, Spain.

$15{ }^{7}$ Singapore Eye Research Institute, The Academia, 20 College Road, Discovery Tower, Singapore.

$16{ }^{8}$ Graduate School of Biomedical Engineering, UNSW Sydney, Sydney NSW 2052, Australia.

$17{ }^{9}$ Department of Regenerative Biomaterials, Radboud University Medical Center, Philips van Leydenlaan 25, 18 Nijmegen 6525 EX, The Netherlands.

19 Corresponding Author: Alireza Dolatshahi-Pirouz (alirezadolatshahipirouz@gmail.com)

Target Journals: Biomaterials

Key words: Sulfated Polysaccharides, Biomaterials, Tissue engineering, Cartilage, Bone, Growth factors, Hydrogels.

*The first two authors contributed equally.

\section{Abstract}

Given their native-like biological properties, high growth factor retention capacity and porous nature, sulfatedpolysaccharide-based scaffolds have shown great promise in a number of tissue engineering applications. Specifically, as they mimic important properties of tissues such as bone and cartilage they are ideal for orthopaedic tissue engineering. Their biomimicry properties encompass important cell-binding motifs, native-like mechanical 
so, scientists in the field have just recently begun to utilise them as building blocks for tissue engineering scaffolds. Most of these efforts have so far been directed towards in vitro studies, and for these reasons the clinical gap is still substantial. This review paper highlights some of the important chemical, physical and biological features of sulfated-polysaccharides in relation to their chondrogenic and osteogenic inducing capacity. Additionally, their usage in various in vivo model systems is discussed. The clinical studies reviewed herein paint a promising picture heralding a brave new world for orthopaedic tissue engineering.

\section{Introduction}

Orthopaedic diseases are the second largest contributor to disability worldwide and are expected to grow rapidly in the foreseeable future due to the aging population.[1] They include debilitating diseases such as osteoarthritis, tendinopathies, osteoporosis, as well as skeletal and joint fractures.[2, 3] The current approaches for addressing this grand challenge rely on various prosthetic, allograft and autograft-based strategies. Even though the prosthetic-based interventions have shown exciting results in recent years, they still face major shortcomings such as suboptimal long-term outcomes, the need for revision surgeries and risk of infection.[4] Allograft and autograft strategies on the other hand impose their own limitations including the possibility of disease transmission, insufficient autologous resources, rejection of allograft tissue and potential need for immunosuppression therapies.[5] To overcome these hurdles a great variety of tissue engineering approaches have been proposed over the years (Figure 1).[3, 6]

The grand goal of tissue engineering is to generate artificial tissues with the capacity to bring normality back to dysfunctional tissues by replacing them with more functional ones.[4] The tissue engineering paradigm involves scaffolds combined with potent cell sources and suitable biochemical signals [7], which together can promote the formation of new organs and tissues.[8] Ideally, these scaffolds emulate key physical and molecular features of the native extracellular matrix (ECM) in order to facilitate cell attachment, proliferation and differentiation and ultimately new tissue growth (Figure 1).[9] The key in this regard is to provide the cells with a native-like milieu with the capacity to guide them into tissue specific phenotypes.[10-13] Generally speaking, bioactivity is included into scaffolds by using: i) insoluble signals, such as bio-ceramics and carbon-based nanocues [14], ii) introducing growth factors and other biological moieties into the scaffold matrix [15], or ii) by incorporating cell adhesion and differentiation promoting oligopeptides (such as the cell binding RGD peptide [16, 17]).

While all of these methods have shown promise in the synthesis of bioactive scaffolds, they still face certain limitations in the clinic. For instance, i) some insoluble signals such as carbon-based nanomaterials can cause a foreign body response that can facilitate tissue fibrosis [18, 19], ii) growth factors often face issues such as loss of bioactivity, low tissue penetration and dosage-dependent toxicity [20] and iii) many of the bioactive oligopeptides do not facilitate the needed intracellular signalling pathways for optimum tissue generation; even though a number of proteins (such as fibronectin[21, 22], collagen[23], osteopontin,[24] vitronectin[25] and fibrinogen[26]) stimulate much more robust intracellular signalling than bioactive oligopeptides[27-30] they are limited by either foreign body responses from the host or in some cases high cost and low scalability. For these reasons, native-like and abundant biopolymers with inherent bioactivity have attracted much attention in biomaterials science. In particular, sulfated polysaccharides are by now widely recognized for their ability to bind to important cell receptors to facilitate cell adhesion, proliferation and differentiation.[31, 32] They can also bind 
to and signal a number of important growth factors such as fibroblast, vascular endothelial and bone morphogenetic protein growth factors for controlled growth factor release; and they can improve growth factor bioavailability by protecting them against proteinase degradation.[31, 33-36]

In simple terms, sulfated polysaccharides can be classified under three distinct categories including i) sulfated GAGs, ii) marine sulfated glycans and iii) chemically sulfated polysaccharides. While the first two categories are inherently sulfated polysaccharides, the third one consists of non-sulfated polysaccharides that are chemically modified with various sulfating agents. Regardless, the bioactivity of sulfated polysaccharides depends on factors such as degree of sulfation and sulfation pattern.[34, 37] For instance, hyaluronic acid (HA)/collagen type I matrices were shown to inhibit differentiation and resorption of osteoclasts, mainly relying on degree of sulfation of HA.[38] To this end, highly sulfated HA was capable of improving bone regeneration in in vitro and in vivo models.[39-41] In other studies, an intimate link between sulfation pattern and chondrogenesis has been proposed.[42] For example, it was shown that chondroitin sulfate (CS) rich in 4,6-O-disulfated disaccharides, had a higher potential to upregulate the expression of important chondrogenic biomarkers when compared to other CS derivatives containing either 4- or 6-O-sulfated disaccharides.[42]

Accordingly, sulfated polysaccharides have been rapidly picked up by scientists in the field in order to manufacture more bioactive scaffolds that can facilitate better skeletal tissue regeneration.[43-53] These scaffolds were made via various fabrication methods such as casting, electrospinning and 3D printing from either individually sulfated polysaccharides or in combination with other biopolymers. Generally speaking, the scaffolds have been used in two different ways to assist osteogenesis or chondrogenesis: i) in conjugation with growth factors to facilitate differentiation of cells via sustained release of growth factors, or ii) in the absence of any growth factors by solely relying on intermolecular interactions with important cell-membrane receptors. $[54,55]$

This paper reviews the most recent progress in sulfated polysaccharide-based scaffolds for skeletal tissue engineering, with particular focus on bone and cartilage tissue engineering. Specifically, three different groups of sulfated polysaccharides, sulfated GAGs, marine sulfated glycans and chemically sulfated polysaccharides, and their usage as building blocks in orthopaedic scaffolds are reviewed; since these polysaccharides present the most promising avenues in this field. This review also highlights the ability of these scaffolds to direct progenitor cells into either chrondogenic or osteogenic differentiation. Finally, application of these scaffolds in various preclinical studies related to mending bone and cartilage defects along with more complex osteochondral lesions are reviewed, as such studies are of utmost importance for bridging the current gap between the laboratory and the clinic.

\section{Naturally Sulfated Polysaccharides}

Sulfated polysaccharides can be derived from the ECM of animal tissues in the form of sulfated GAGs or from plants such as marine algae in the form of alginate, carrageenan, fucoidan and ulvan (Figure 2). The sulfate groups in the abovementioned biopolymers can also be chemically conjugated to the sugar backbones of nonsulfated molecules such as HA, chitosan, alginate and cellulose. Along these lines, this section is divided into three subsections dealing with sulfated GAGs and polysaccharides derived from natural sources as well as sulfated polysaccharides that are custom-made in the laboratory. Notably, the wide variety of sulfated polysaccharides 


\section{$1 \quad 2.1$ Glycosaminoglycans (GAGs)}

Sulfated GAGs are present in the ECM, cellular membrane and intracellularly within eukaryotes (Figure 2). They therefore, play an essential role in modulating extracellular and intracellular interactions. In simple terms, GAGs can be defined as negatively charged heteropolysaccharides, whose disaccharide units are made from repeating disaccharide units consisting of either an amino sugar (glucosamine or galactosamine) or a uronic acid (iduronic or glucuronic acid). Based on their disaccharide composition, they are grouped into four different families including heparin/heparan sulfate, chondroitin/dermatan sulfate, keratan sulfate and HA. While heparin, heparan, chondroitin, dermatan and keratan sulfate are sulfated and post-translationally synthesised via attachment to a core protein, HA is non-sulfated and synthesised at the cell surface without a protein core. Importantly, GAGs can differ significantly from one another in terms of bioactivity and structural complexity depending on their specific biosynthesis pathway and source of derivation.[56]

\section{Heparin and Heparan Sulfate}

Heparin is a highly sulfated GAG only produced by connective tissue mast cells that exclusively decorates the protein core of serglycin. [57] In contrast, heparan sulfates (HS) decorate intracellular, ECM and cell surface proteoglycans and are produced by almost all cell types. Specifically, they participate in a wide range of biological events including cell proliferation and differentiation, immune responses, as well as angiogenesis.[58-61] Both heparin and HS are composed of repeating disaccharide units of either iduronic or glucuronic acid and glucosamine units but with less iduronic acid and less overall sulfation in HS compared to heparin. Importantly HS does not contain sulfation at the C3 position and does not possess anti-coagulant activity.[62-64] They also interact with a variety of proteins, including heparin-binding growth factors, which together with their cell signalling role, make them ideal choices for scaffolding materials.[60]

Heparin has been widely explored in tissue engineering, owing to its ease of supply, especially in the clinical as an anticoagulant. It is also often used as an analogue of HS.[65-67] Heparin and HS bind to a range of proteins via electrostatic interactions that are controlled by its three-dimensional structure, anionic nature and sulfation patterns. Heparin is known to enhance the osteogenic potential and bioavailability of bone morphogenetic protein2 (BMP-2) through its binding, stabilization and presentation to cells.[68-70] Indeed, in a study by Hettiaratchi $e t$ al. [71] it was shown that methacrylated heparin microparticles could bind high quantities of BMP-2, vascular endothelial growth factor (VEGF) and fibroblast growth factor-2 (FGF-2), which in turn could stimulate alkaline phosphatase (ALP) activity in skeletal myoblasts (C2C12) and increase the cell division rate. Notably, such heparin microparticles typically demonstrate better presentation of growth factors in comparison to gelatin microparticles and soluble heparin; something which has been speculated to arise from heparin's higher charge density.[71] Similarly, PLGA microspheres when functionalised with both heparin and BMP-2, could significantly up regulate MG-63 osteosarcoma cell differentiation as seen through the enhanced expression of osteocalcin (OCN) and osteopontin (OPN), whilst simultaneously increasing both ALP activity and deposition of important bone minerals.[72]

However, heparin's anticoagulant capacity can hinder bone regeneration through antithrombin III activation, which can prevent the accumulation of various tissue regenerative growth factors and cytokines in the defected bone region. Thus, the lesser negatively charged HS could be a more useful bioactive supplement. To this end, Bramono et al. [73] compared the osteogenic potential of heparin and HS from various sources; as regulators of 
BMP-2 activity, and found that heparin could up regulate osteogenic differentiation of C2C12 cells (induced by BMP-2) in the short term, however they did not observe any significant BMP-2 stimulated bone matrix mineralisation after 14 days. Interestingly, HS delivered BMP-2 in a prolonged and controlled manner, at more physiologically relevant concentrations whilst retaining its osteogenic activity when compared to heparin. This was thought to be associated with the higher growth factor binding and signaling capacity of HS compared to heparin which enables the more efficient presentation of osteogenic ligands to their cell associated receptors.[74] HS has also been shown to regulate other growth factors in the transforming growth factor beta (TGF- $\beta$ ) superfamily. For instance, Chen et al. [75] demonstrated that, in the presence of TGF- $\beta 3$, HS induced chondrogenic differentiation of human MSCs whilst activating important TGF- $\beta$ related signaling pathways. Similarly, heparin in combination with a self-assembling peptide (RAD 16-I) could drive adipose-derived stem cells (ADSCs) into the chondrogenic lineage as evidenced by collagen type II up regulation; a phenomenon that was speculated to arise from heparin's affinity towards VEGF.[76] More recently, a biphasic silk fibroin biomaterial incorporating heparin was reported to increase growth factor retention and thereby preventing the undesired initial burst-like release that is so common in many traditional scaffolds.[77] Interestingly, the addition and controlled release of TGF- $\beta 2$ and GDF5 (growth differentiation factor 5) into the scaffold up-regulated chondrogenic markers, including SOX9, aggrecan and collagen type III (Figure 3).

In summary, several studies have demonstrated the versatility of heparin and HS to efficiently deliver and preserve the function of important chondrogenic and osteogenic growth factors. As mentioned, the prominent anticoagulant capacity of heparin can diminish the accumulation of growth factors and cytokines in a bone defect site and subsequently hinder tissue regeneration. HS, the less sulfated heparin analogue, on the other hand holds promise as an alternate delivery vehicle without such undesirable side effects. In this regard, HS has already showed promise at permitting sequestration and controlled local delivery of growth factors resulting in an improved bone and cartilage matrix production. Overall, HS and heparin-based biomaterials have shown immense promise in multiple branches of tissue engineering including but not limited to growth factor and cytokine delivery vehicle for bone and cartilage tissue regeneration.

\section{Chondroitin Sulfate}

Chondroitin sulfate (CS) is the most abundant GAG found in vertebrate and invertebrate ECM and decorates intracellular, ECM and cell surface proteoglycans. It is a linear polysaccharide composed of repeating disaccharide units of glucuronic acid and galactosamine that can be sulfated at carbons 2 on the glucuronic acid, and 4 and/or 6 on the galactosamine, which provide heterogeneity in structure.[78] Aggrecan is the major CS proteoglycan in cartilage that binds to HA to form aggregate structures that have a high water retention capacity and provide the hydrodynamic weight bearing properties of cartilage.[79] CS has been shown to stimulate the synthesis of HA, aggrecan, glucosamine and collagen II, as well as preventing chondrocyte apoptosis and cartilage degradation by inhibiting ECM degrading enzymes. Accordingly, CS has been greatly utilized for repairing cartilage as well as assisting stem cells to undergo chondrogenic differentiation. [80] For a more in-depth analysis of the influence of CS hydrogels on stem cell fate the reader is referred to a comprehensive review published recently by Farrugia $e t$ al. [81] 
A number of recent studies have harnessed the abovementioned biomimicry properties of CS in cartilage tissue engineering with exciting outcomes. For instance, a study by Levett et al. [82] aimed to enhance chondrocyte behaviour in gelatin methacrylate-based (GelMA) hydrogels by incorporating GAGs including HA methacrylate (HAMA) and CS methacrylate (CSMA) into the hydrogels; both separately and together. Interestingly, they found that the integration of HAMA enhanced chondrocyte re-differentiation and improved matrix distribution, whereas CSMA showed marginal improvements over both the GelMA control and GelMA/HAMA/CSMA triple composite. This means that HAMA positively influences bioactivity and the mechano-physiological properties of GelMA hydrogels when compared with CSMA. Although, HA provides the biochemical cues for chondrogenesis, it was shown that the inclusion of CS in the HA hydrogels can upregulate mRNA expression of chondrogenic markers, while decreasing expression of the hypertrophic markers that are normally associated with HA hydrogels.[84] Additionally, incorporation of CS into HA hydrogels led to an increase in GAG accumulation both in vitro and in vivo. Similar results were observed by Costantini et al. [85] during bioprinting of bone marrow derived hMSCs in a composite matrix containing GelMA, HAMA and CS amino ethyl methacrylate (CSAEMA). In the absence of HAMA, the ratio of collagen II/collagen I and collagen II/collagen X increased suggesting neocartilage formation, whereas differentiation towards hypertrophic cartilage was observed with HAMA alone. This may be due to the stiffness increase from $59 \mathrm{kPa}$ (GelMA/CS) to $100 \mathrm{kPa}$ (GelMA/CS/HAMA), as MSC differentiation is sensitive to interface stiffness.[86, 87] In summary, the chemical composition, network density and stiffness of the 3D microenvironment in combination play an important part in determining the chondrogenic potential of MSCs, with CS showing the most promising cartilage regenerative capacity.

CS has also been employed together with other biopolymers such as polyethylene glycol (PEG), chitosan, and alginate to constitute bioactive scaffolds for cartilage tissue engineering.[46, 88-93] In a noteworthy example, with the aim of evaluating the effect of CS sulfation degree on its interaction with positively charged growth factors, researchers made two different types of scaffolds composed of poly(ethylene glycol)-diacrylate (PEGDA) with either CS or desulfated CS.[89] In vitro experiments demonstrated that the release of a positively charged model protein, histone, from hydrogels containing desulfated CS resulted in an increased histone release when compared to a hydrogel containing normal CS, indicating that sulfation plays an essential part in modulating protein interactions with GAG hydrogels, and thereby also the growth factor release profile. Interestingly, in chondrogenic medium, MSCs in hydrogels containing desulfated CS had significantly higher expression of collagen II and aggrecan at day 21, compared to PEG control scaffolds or CS containing scaffolds. This was speculated to arise from the augmented TGF- $\beta 1$ pull-down from culture media caused by the presence of CS in the hydrogels.

In another study, a biomaterial composed of chitosan and CS was utilized in engineering cartilage tissue.[46] The in vitro results with a pre-chondrocyte cell line (ATDC5) showed that chitosan/CS induced a more collagen II/collagen I ratio (a characteristic of hyaline cartilage formation) after 21 days, when compared to pristine chitosan. Furthermore, the collagen X expression in chitosan/CS showed an increase after 21 days compared to pristine chitosan scaffolds, indicating that these scaffolds can drive ATDC5 cells into a hypertrophic state. CS has also been employed in conjugation with alginate to establish porous scaffolds for chondrogenesis of hMSCs.[93] After 14 days, it was shown that under chondrogenic conditions total collagen and GAG contents 
Apart from cartilage tissue engineering, CS has been utilized to promote osteoblast adhesion for engineering of bone tissue.[94] In this respect, Vandrovcová et al. [95] coated PLGA with collagen I with and without CS and showed that CS improved both the osteoconductivity and osteoinductivity of the (osteoblastic) MG-63 cell line, observed through the increased proliferation and upregulation of osteocalcin, as compared to pristine collagen I coatings. Similarly, titanium implants have also been coated with CS/collagen[96] or CS,[97] as sulfated GAGs are known to bind calcium and calcium phosphates such as hydroxyapatite [98]. The former compared three forms of CS (4-sulfated CS (CS A); 6-sulfated CS (CS C) and dermatan sulfate (CS B)), and found that both CS A and CS B stimulated local osteoblast adhesion. We also note, that the study by Dudeck et al. [97] demonstrated a synergistic effect between CS and hormone replacement therapy in an osteoporotic rat model, and thus indicates that CS scaffolds could open new therapies for osteoporosis.

In summary, CS has been used in conjunction with biopolymers to form more functional composite biomaterials that can facilitate both chrondrogenisis and osteogenesis. When used with cartilage forming cells, it has been seen that the inclusion of CS increases the expression of collagen II, while facilitating a more hyalinelike cartilage formation, as a result of enhanced binding with growth factors and integrin-mediated cell-matrix interactions the CS structure, and specifically the location of the sulfates on the CS backbone, directly influences its ability to bind to cells and direct their differentiation. Therefore, CS holds great promise for skeletal tissue engineering since it can both have an impact on chondrogenesis and bind to important components of the hard phase of bone; all because of its many sulfate groups.

\subsection{Marine sulfated Glycans}

Over $70 \%$ of the earth's surface is inundated by oceanic environments, rich in biodiversity. Among these marine organisms lies algae and seaweed that are abundant with bioactive compounds of use in the field of biomedicine owing to their numerous health benefits stemming from their anti-inflammatory, anti-cancer, anticoagulant and immunomodulatory properties. $[88,99,100]$ Although seasonal disparities can influence their overall composition,[101] their sustainable cultivation is not constrained by climate as with various terrestrial plant species. Notably, some of these algae are also made up of monosaccharides joined by glycosidic bonds (Figure 2) that resemble GAGs and they can promote protein binding and cell growth without giving rise to immunogenicity. As with other GAG-like polymers, the bioactivity of sulfated marine sugars depends on their composition, molecular weight, degree and location of sulfate groups. The three most prevalent marine-based sulfated polysaccharides currently used in biomedicine are carrageenan, fucoidan and ulvan, derived from red, brown and green algae, respectively.

\section{Carrageenan}

In simple terms, Carrageenans (CARs) can be described as linear and water-soluble anionic-sulfated polysaccharides. They are derived from red algae of the class Rhodophyceae and identified based on their disaccharide sulfation. They have previously been successfully exploited in cartilage and bone tissue engineering applications, owing to their thermoreversible gelling behaviour in the presence of non-toxic cations, as well as their ability to facilitate bone apatite formation.[102-110]. As a noteworthy example, Popa et al. [102] demonstrated that kappa ( $\kappa)$ - CAR hydrogels were capable of supporting the proliferation and chondrogenic 
modulus and viscoelastic properties possibly related to the ECM deposition from the cells. Additionally, following compression, hydrogel's mechanical properties were observed to be in the range of native human cartilage. In another study, Oliveira et al. [111] investigated how variations in the primary structure of CARs can influence bone mineralisation. They compared the osteogenic properties of three different CAR sugar backbones, kappa ( $\kappa)$, iota (1), and lambda $(\lambda)$, within a chitosan/polycaprolactone (PCL)-based scaffold. In this respect, it was shown that bone apatite formation varies significantly between different CAR species. Specifically, of the three CARs employed, the t-variant demonstrated significantly higher biomineralization, possibly due to an increased affinity for various bioactive compounds from the osteogenic media as a result of higher sulfur, oxygen and nitrogen content within its sugar-like backbone. In a similar vein, the osteogenic capacity of a composite containing tCAR/chitosan/gelatin was recently explored.[112] Here, the researchers found that the inclusion of gelatin with its native RGD peptides and chitosan with its favorable cationic and osteogenic properties,[113] into the CAR hydrogel network, promoted the osteogenic differentiation of ADSCs. Notably, they found that the inclusion of a 10 wt \% t-CARs substantially increased the ALP activity of encapsulated cells in comparison to the composites containing 0,5 and $15 \mathrm{wt} \%$ of t-CAR. Correspondingly, an ostegenic-specific histology assay suggested that the 5 and 10 wt \% 1-CAR-based composites caused higher mineral deposits following a 28-day in vitro study than the other groups. In another recent investigation, $\kappa$-CAR was blended into biodegradable polyesthers to consummate a biocompatible scaffold for bone tissue engineering.[50] Interestingly, the authors found that like the other studies reviewed herein the presence of $\kappa$-CAR could facilitate the formation of nanosized apatite crystals when compared to pure polyesters, which instead gave rise to non-native-like and larger microsized crystals. Of interest, the introduction of $\kappa-\mathrm{CAR}$ in the polyester material also enabled tailored degradability. In a related study, Liang $e t$ al. [51] found that the expression of genes specific to cartilage (SOX9, collagen II and aggrecan) were up regulated with increasing CARs concentrations within chitosan, when compared to pristine chitosan. They also showed that CARs promoted cellular responses such as adhesion, viability and proliferation in the composite hydrogel. These benefits were attributed to the chemical similarities between CARs and CS, which is widely recognized for its chondrogenic capacity.

The thermoreversible and thixotropic gelling behaviour of $\kappa-\mathrm{CAR}$ under physiological conditions also makes them suitable to be used as injectable hydrogels in cartilage tissue engineering, as evidenced by a recent study by Rocha et al.[114] Specifically, in this study, it was found that ADSC-laden $\kappa-C A R$ hydrogels cultured in TGF- $\beta 1$ supplemented growth media did not induce chondrogenic differentiation, though when used with chondrogenic medium, the cells developed a spherical, chondrogenic-like phenotype. Likewise, immunohistochemical analysis revealed increased collagen II deposition following the integration of TGF- $\beta 1$ in the $\kappa$-CAR hydrogels under chondrogenic conditions, suggesting the production of cartilage-specific proteoglycans. Interestingly, the heated gelling conditions did not elicit thermal stress on encapsulated hASCs following live-dead staining, justifying their potential future use as in situ forming hydrogels in cartilage tissue engineering.

\section{Fucoidan}

Fucoidan is a sulfated polysaccharide stemmed from the cell-wall matrix of brown seaweed. It contains a significant amount of L-fucose and sulfate ester groups which varies based on the source species.[100] The species that is most frequently used in the field, is - Fucus vesiculosus - which typically gives rise to Fucoidan consisting 
of 1,2- $\alpha$-fucose, with its sulfate groups primarily located at C4 position.[115] Interestingly, fucoidan has been demonstrated to interact with transforming growth factor (TGF)- $\beta_{1}$, which was speculated to be associated with its heparin-like chemical structure,[116] and like the CARs, fucoidan can also facilitate bone-like apatite formation.[117] Specifically, it was demonstrated that the addition of fucoidan promoted osteocalcin and ALP production whilst supporting human bone marrow stromal cell (hBMSC) growth. The increase in ALP was indicative of initial osteogenic differentiation, which happened after a rapid cell division, a stage in osteogenic differentiation of stromal cells in culture. Interestingly, they also found that fucoidan could more than double the compressive strength of the scaffolds from $191 \pm 5 \mathrm{KPa}$ to $414 \pm 3 \mathrm{MPa}$, something that could come to use later, due to the intimate link between cartilage/bone formation and biomaterial stiffness.[118] In another study, Puvaneswary et al. [49] developed a porous fucoidan scaffold to influence bone mineralisation and apatite formation. These scaffolds promoted hBMSC attachment, proliferation and differentiation. Though the lengthy process of mineralisation was not significant, upregulation of collagen I under osteogenic conditions demonstrated osteogenesis within the fucoidan composite. Additionally, Runt-related transcription factor-2 (RUNX2) and osteonectin $(\mathrm{ON})$ were significantly upregulated compared to the chitosan only hydrogel.

Owing to the TGF- $\beta$-binding properties of fucoidan, it was also exploited for cartilage tissue engineering applications. For instance, Karunanithi et al. [119] studied the chondrogenesis of encapsulated hMSCs within a fucoidan-alginate composite. The results revealed that hMSCs cultured in chondrogenic medium supplemented with fucoidan expressed a higher level of chondrogenic markers (including tenascin-C, SOX9, collagen II, aggrecan and cartilage oligomeric matrix protein). In addition, the cultures expressed a significantly lower level of hypertrophy markers (including Col X and Runx2), when compared to alginate hydrogels. Furthermore, cells encapsulated in the fucoidan-alginate hydrogel produced a higher GAG content at day 21 when compared to alginate hydrogels, which is a widely recognized indicator of mature chondrocyte phenotype. Thus fucoidan may enhance the chondrogenic differentiation of stem cells owing to its affinity to multiple growth factors, such as TGF- $\beta 1$. Likewise, cell condensation - a hallmark for chrondogenic differentiation - were observed in this study, which puts further emphasis on the promise that Fucoidan holds in cartilage tissue engineering.

Ulvan

Ulvan, a lightly branched anionic-sulfated polysaccharide, is derived from the cell wall of green algae; and consist of sulfated rhamnose, iduronic and glucuronic acids.[120] The ulvan sugar share a chemical similarity with GAGs, due to its glucuronic acid and sulfate groups.[88, 121] As with the previously investigated marine glycans, ulvan has been employed in conjugation with chitosan to generate osteogenic coatings for titanium implants. To this end, coatings seeded with 7F2 osteoblasts showed complete confluency after 6 days; something significantly different as compared to cells seeded on pure ulvan or pure chitosan. From this point-of-view ulvan/chitosan composite induced the attachment and proliferation of 7F2 osteoblasts while maintaining the cell morphology and viability. In a related study by Dash et al. [122] ulvan was used for bone tissue engineering applications. Purposely, the group introduced methacrylate groups to the ulvan backbone to further increase the physiological stability of the hydrogel through UV-crosslinking. Hydrogels were incubated with ALP at varying concentrations to gauge mineralisation capacity, as mineralisation is known to promote bioactivity through the formation of chemical bonds with surrounding bone tissue after implantation. The lowest methacrylated-ulvan 
group, saw the highest concentration of ALP resulting in pre-osteoblast cells differentiating towards an osteogenic lineage, as interpreted from increased ALP activity and a reduction in cell proliferation.

Overall, these naturally sulfated marine glycans have seen limited use thus far in orthopaedic tissue engineering applications. Since they're known to have chemical compositions that mimic several ECM-based GAGs and proteoglycans there's no doubt they could be used to drive the R\&D engine of the next-generation of biomaterials for orthopaedic tissue engineering. Especially, their strong affinity towards a wide range of tissue regenerative growth factors makes them ideal growth factor delivery vehicles, which in turn further improve their tissue regeneration capacity. Additionally, their high abundance and sustainability along with reduced immunogenicity strongly advocates their promise in the broader field of tissue engineering.

\subsection{Chemically sulfated}

The biological features of sulfated polysaccharides from mammalian and plant-based sources are vast. In fact, their bioactivity is a function of molecular weight, sugar-backbone variant and sulfate degree[123] However, naturally-derived polysaccharides typically give rise to batch-to-batch variations, which further hinders the reproducibility of their ensuing biophysical properties.[124, 125] As a result, in an effort to produce sulfated polysaccharides with more specific and controllable functional properties, researchers have started to chemically manipulate non-sulfated polysaccharides such as HA, chitosan, alginates and cellulose, with either sulfate groups or sulfate-containing biomolecules. Controlled chemical sulfation of these polysaccharides can be achieved through various surface immobilisation strategies including chemical binding[126] and electrostatic assembly.[127] Modifying or combining these polysaccharides with sulfate-containing moieties could exploit their native chondrogenic or osteoblastic potential whilst prolonging growth factor delivery to promote proliferation and differentiation of tissue specific stem cells, as well as circumventing shortcomings such as hypertrophy or rapid enzymatic scaffold degradation.[128]

Hyaluronic acid (HA)

HA is a naturally occurring GAG, that has been widely utilised in tissue engineering as it possesses cell surface receptors such as CD44 that enable cell binding,[129] and is immunoneutral at the same time.[130] Indeed, the CD44-based cell binding receptor has been utilised and shown to increase chondrogenesis.[82, 131] Various, groups have also studied the effect of modifying the HA with sulfate groups, to enable sustained growth factor delivery through improved growth factor binding. For instance, Xu et al. [132] investigated the effect of decorating HA with heparin. It was seen that when MSCs were seeded onto a HA-heparin hydrogel with BMP-2 present, there was significant upregulation of mRNA and key chondrogenic genes including collagen II, SOX9 and aggrecan, as compared to pristine HA. These improvements can be attributed to the heparin subgroups that contain sulfate groups, which were seen to have a higher binding capacity for BMP-2. Importantly, a sustained release profile over 13 days was observed, compared to pristine HA which displayed an initial burst release profile.

In a similar vein, Jha et al. [133] chemically modified HA with HS-bearing perlecan domain I perlecan, a recombinantly produced proteoglycan. Here, the HA-perlecan hydrogel exhibited the ability to bind significantly more BMP-2 as compared to HA alone and promoted chondrogenesis. Likewise, Srinivasan et al. [134] chemically modified HA with HS and demonstrated a targeted and controlled delivery of BMP-2 for cartilage tissue engineering. For bone tissue engineering HA-based hydrogels have been chemically modified with heparin 

was observed, with sustained release only seen in heparin containing hydrogels, which in turn maintained the osteogenic potential of BMP-2 over 28 days. Another study by Hintze et al. [136] compared HA, sulfated HA and CS hydrogels, and found that, native HA, low sulfated HA and CS showed low affinity for all TGF- $\beta$ isoforms. Specifically, the highly-sulfated HA had the greatest affinity for TGF- $\beta 1$ and TGF- $\beta 2$ but not TGF- $\beta 3$.[137]

Overall, HA has proven to be a favorable material for various tissue engineering applications as it contains the important CD44 receptor and is capable of binding to important tissue regenerative growth factors. Some studies in the field also suggest that by decorating HA with sulfated materials such as heparin, perlecan and CS, it is possible to significantly increase its affinity towards important growth factors for skeletal tissue engineering as well as delaying their release in a controlled manner.

\section{Chitosan}

Chitosan is a non-sulfated, linear polysaccharide with a semi-crystalline and biodegradable nature. It's typically derived from chitin extracted from insects, crustaceans and fungi (Figure 2). Chitosan is known to have intrinsic antimicrobial properties against fungi and bacteria.[138] The molecular weight of chitosan varies from $300-1000 \mathrm{kD}$ and it is comprised of glucosamine and $\mathrm{N}$-acetyl glucosamine linked by $\beta(1-4)$ glycosidic bonds. Notably, chitosan behaves as a polycation under acidic conditions, and thus is capable of forming hydrogels in the presence of polyanions and polyelectrolytes. Additionally, the degradability of chitosan directly relates to its degree off crystallinity and can thus be tailored to correspond to the targeted tissue.[139]

To even further improve the already impressive biological properties of chitosan, tissue engineers have recently tried to modify its polymeric backbone with sulfate groups. For instance, Cao et al. [140] transformed chitosan into 2-N, 6-O-sulfated chitosan (2,6SCS); and demonstrated that this particular sulfated chitosan is useful for sustained and dose-dependent BMP-2 delivery among many sulfated variants.[140] In a follow-up study they made a comparison between BMP-2-gelatin (G)-based scaffolds, BMP-2 loaded 2,6SCS chitosan nanoparticles (BMP-2/NPs) incorporated into these gelatin scaffolds (BMP-2/S-NP/G) and a BMP2-2,6SCS-G composite. To this end, the authors found that the BMP-2/S-NP/G variant could significantly prolong the growth factor release and up-regulate in vitro ALP activity as compared to the other variants (Figure 4); something which was thought to be associated with the synergistic action of released BMP-2 and the unique material properties of 2,6SCS sulfated nanoparticles.[141] Interestingly, the addition of nano-particles also had an impact on the mechanical properties of the scaffold, thereby significantly prolonging its degradation time, to create an optimal condition for balancing scaffold removal with the deposition of fresh bone tissue. Building on these results, a recent approach by Pan et al. [142] demonstrated that 2,6SCS can also be used to improve the angiogenic and osteogenic capacity of BMP-2, confirmed both on a protein and genetic level. In another recent study, Cao et al. used 2,6SCS in combination with poly(lactide-co-glycolide) (PLGA), to manufacture a composite scaffold (S-PLGA). Here they demonstrated that the BMP-2 binding efficiency within the PLGA scaffold could increase almost 10-fold in the presence of 2,6SCS. The release profiles of BMP-2 were 30\% slower in S-PLGA scaffolds as compared to pristine PLGA. In the same study, BMSC cells showed an elongated and spindle-shaped morphology when interacting with the hydrophilic surface of S-PLGA. Additionally, these cells were seen to circumvent Noggin inhibition, a BMP antagonist that binds extracellular BMP-2, which in turns inhibits important receptor interactions ultimately 
soluble molecule that is able to interact efficiently within the biological environment in contrast to the acid soluble starting material. Sulfate modification of this molecule has been achieved at the 2N as well as C2, C3 and C6 positions on the chitosan backbone.[143, 144] These sulfated derivatives bind and signal members of the fibroblast growth factor family replicating the activities of HS. While chitosan-arginine has been reported to induce osteogenesis in primary chondroblasts without exposure to osteogenic medium, sulfated chitosan-arginine could facilitate chondrogenesis instead.[143] These data demonstrate how subtle changes in sulfation affect cell phenotype and can direct stem cell differentiation.

In summary, the high abundance of chitosan in nature along with its favorable biocompatible and biodegradable properties makes it an attractive biomaterial for skeletal tissue engineering. The modification of chitosan with sulfate groups can further improve the already amazing bioactivity of this material. Indeed, the controlled introduction of sulfate groups onto chitosan's backbone can expand its use as a potential coagulator and a growth factor delivery vehicle.[142] Interestingly, the cationic nature of chitosan enables negative GAGs and proteoglycans to easily be incorporated into such scaffolds to promote better tissue regeneration. What's more, sulfated chitosan is in many ways structurally similar to GAGs, and thus share many of the same biological properties; as its capable of modulating both cell morphology and function - two important hallmarks of cell proliferation and differentiation.[145, 146] Overall, these exciting biomaterial properties of chitosan justify it's continued usage as a novel biomaterial in orthopaedic tissue engineering applications.

Alginate

Alginate is a sustainable polysaccharide extracted from brown algae (Pheaophyceae) and less frequently from gram-negative bacteria (Azotobacter and Pseudomonas sp.). Alginates are linear-anionic polymers with favorable biocompatibility for various tissue engineering applications (Figure 2).[147, 148] Notably, alginate has the capacity to form ionic hydrogel networks through chelation with divalent cations, such as $\mathrm{Ca}^{2+}$, broadening its use towards drug delivery[149]. Additionally, due to the innate adhesive and tailorable shear thinning viscoelastic properties of alginate it has found widespread use in bioprinting applications.[150-152] As with other plant-based hydrogels, alginate does not natively support cell adhesion and has been described as a "blank slate" by many engineers in the field.[153] Even still, alginate can be customised through sulfation and peptide modifications to control the phenotypes of encapsulated osteoblasts,[154] chondrocytes[155] and hMSCs.[156]

Alginate sulfation based on sulfur trioxide $\left(\mathrm{SO}_{3}\right)$ [157] and sulfuric acid[158] treatments have been widely used over the years. To this end, some studies have demonstrated that such sulfated alginates can retain growth factors and promote chondrogenesis through various cellular signaling pathways;[159] and for these reasons they are considered as heparin analogues (Figure 5). Along these lines, Mhanna et al. [160] employed an $\mathrm{SO}_{3} /$ pyridine method of alginate sulfation for cartilage tissue engineering. In this study, the formation of ionic networks was restricted to a degree of sulfation of 0.8 (per monosaccharide unit), as higher degrees of sulfation (2.6) did not facilitate hydrogel formation, possibly due to strong electrostatic forces and/or steric effects between adjacent polymers. Interestingly, they found that sulfation maintained the proliferative capacity as well as phenotype of encapsulated chondrocytes, in contrast to previous studies showing initial dedifferentiation in a non-sulfated hydrogel microenvironments.[161-163] The introduced sulfate groups also influenced Ras homolog gene family member A (RhoA) activity, which is known to be associated with chondrocyte proliferation and 
differentiation[164]; though the expression of collagen I and collagen II as well as proteoglycan synthesis was not significantly impacted.

3

Thus, sulfated alginate-based scaffolds are promising alternatives to mammalian derived GAGs due to their biocompatibility, low immunogenicity, protein retention capacity and the great variety of readily implementable gelling and functionalisation strategies that can improve their bioactivity. Their extensive and continued use will definitely empower researchers with the knowledge to effectively understand the regulatory role of sulfatedalginate in extracellular and intracellular interaction, something, which hopefully will lead to their more frequent use in skeletal tissue engineering in the foreseeable future.

\section{Cellulose}

Cellulose is the most abundant natural polysaccharide available in the world.[165, 166] Its chemical structure consists of unsubstituted, linear glucose homosaccharide with six available hydroxyl groups. Intriguingly, it has been seldom used in tissue engineering, potentially due to difficulties in hydrogel assembly caused by solubility inadequacies.[167] The sulfation of cellulose can improve solubility, through the disruption of intermolecular hydrogen-bonds[168] to potentially broaden its applicability towards various tissue engineering applications.[169]

One study by Huang et al. [170] explored the use of sulfated cellulose scaffolds for cartilage tissue engineering. Initially MSC induction media was spiked with a fully sulfated form of sodium cellulose (NaCS) leading to a significant upregulation of collagen II and aggrecan. In the same study, $\mathrm{NaCS}$ was combined with gelatin to develop scaffolds through electrospinning. Interestingly, the scaffolds with the lowest concentration $(0.1 \%)$ of NaCS added to induction media resulted in the highest production of collagen II both on a protein and genetic level after 56 days of culture. Additionally, cells on the $1 \%$ and $5 \% \mathrm{NaCS} /$ Gelatin-based scaffold showed low collagen $\mathrm{X}$ production, suggesting higher $\mathrm{NaCS}$ may result in a reduced propensity towards hypertrophy. These higher sulfate concentrations may have an inhibitory effect on chondrogenesis because of irreversible growth factor-biomaterial bindings, which in turn can comprise the release and delivery of TGF- $\beta 3$ to the targeted cells.[171] The same group took this a step further and introduced partially sulfated cellulose (pSC) into gelatin hydrogels instead, and discovered an enhanced expression of chondrogenic markers (collagen II/collagen I ratio, aggrecan and SOX9) upon increasing pSC concentration in the scaffolds, indicating the potential of pSC as a scaffold for cartilage tissue engineering.[172]

For these reasons, cellulose sulfate is an interesting carrier for growth factor delivery in cartilage tissue engineering and could have broader uses in the foreseeable future due to its abundance, sustainability and reduced immunogenicity. Specifically, the backbone sulfation of cellulose allows for precise control over the sulfation pattern and sulfation degree, and thereby enables the biological properties of such scaffolds to be fine-tuned in a customizable manner. The range of available chemical modifications can also pave the way for tuneable mechanical and pharmaceutical properties, and could thereby potentially enable an even greater variety of biomaterials. [173] [174]

\section{Tissue engineering}


While sulfated polysaccharides have been shown to successfully act as delivery vehicles for growth factors in an in vitro environment, their ability to elicit this response in an in vivo model needs to be evaluated as well. Indeed, many tissue engineering approaches have shown significant benefits in in vitro studies yet when they progress to animals models they show some limitations.[28] Understanding, whether the successful in vitro strategies also show promise in an in vivo setting, is therefore critical to successfully translate tissue engineering strategies from the laboratory and into the clinic. This section, highlights recent advances in translating the hard tissue regenerative potential of scaffolds made from sulfated polysaccharides in various animal models both alone, in combination with various growth factor or with other biopolymers.

\section{9}

\subsection{Bone}

The number of people at risk of bone fractures has grown steadily in most parts of the world due to the ageing population. In 2015 around 160 million people worldwide experienced a bone fracture; a number that is expected to double to 320 million by the end of 2040.[175] Traditional clinical therapies for mending bone fractures rely on various forms of casts to fixate the broken fracture to enable the native bone to heal itself on its own terms, however, native bone displays a restrictive regenerative capacity, that is haunted by a number of challenges including non-anatomical reduction of the fracture, a-vascular necrosis, as well as non-union and malunion fracture healing.[176] These issues are more prevalent in older people and will thus grow steadily in the near future as the median lifetime is expected to increase significantly in the coming decades. Autologous bone grafts are commonly utilized to promote osteoconduction and osteoinduction in bone defects to avoid the abovementioned scenarios. While these grafts have shown some promise for healing bone defects, they require multiple invasive surgeries and are hindered by low availability and donor site morbidity associated with relocating native bone tissue from the patient's own bone and into the defect site.[177] Allografts on the other hand are limited as a consequence of lack of available donor tissues and unwanted foreign body responses; and bone implants in some cases do not facilitate sufficient bone healing and therefore revisions surgeries are common with this methodology.[178]

For these reasons, a number of bone tissue engineering strategies have emerged to address this critical challenge by delivering the promise of a better method to mend bone defects.[179] As such, these approaches rely on developing synthetic bone tissues by combing 3D biomaterials with stem cells either exogenously or by recruiting them from native bone-tissue in a post-implantation scenario. The 3D biomaterials have the potential to drive stem cells into bone-like cells that under the right conditions can form mature tissues either in the laboratory or within the body depending on which one of the abovementioned strategies has been employed (Figure 1). However, many of the tissue engineered scaffolds explored to date have not reached this full potential and in many cases fall short of the performance of autografts.[180] A number of studies, including those by Wang et al. [177] and Lee et al. [15] suggest that such results could be related to the uncontrolled release of growth factors that collaterally interfere with untargeted cells. As sulfated polysaccharides can bind and regulate the signalling of a number of important growth factors they are likely to be essential components of next-generation biomaterials for bone tissue engineering.

Indeed, sulfated polysaccharides are considered one of the most important biological and mechanical components of the native ECM of hard tissues.[181] They have therefore in recent years emerged as new and 
promising building blocks for bone tissue engineering scaffolds.[182] Heparin is one of the most widely employed sulfated polysaccharides in this respect, due to its ability to capture, stabilize and present growth factors to bone progenitor cells in a controllable manner. For instance, Yang et al. [183] developed heparin-conjugated fibrin scaffolds for orthotopic in vivo models to control the release of BMP-2 in order to prolong the bioactivity of ALP. This prolonged activity ultimately translated itself into significant improvements in bone mineralization when compared with pristine fibrin scaffolds. Notably, by using heparin, they were able to obtain a similar amount of new tissue formation with lower concentrations of BMP-2 than previously reported in the literature.[184] However, some studies have reported that exogenous heparin under certain circumstances reduces the bioactivity of osteogenic biomolecules and can thus compromise the bone healing process, by inhibiting the binding of BMP2 to the BMP receptor. What's more, the potent anticoagulant activity of heparin is, by many in the field, thought to be counterproductive for bone growth.[185]

To address these issues, sulfated chitosan, has been used as an alternative due to its good biocompatibility and similar growth factor binding ability as heparin without the abovementioned native biological issues associated with heparin.[186] In this direction, Zhou et al. [187] synthesized BMP-2 loaded chitosan with varying degrees of sulfation and compared their responses in vivo. These in vivo results revealed that the most sulfated chitosan-based scaffold was the best promoter of BMP-2 bioactivity, and could even surpass the bone regeneration capacity of heparin-based scaffolds. Similarly, Bai et al. [188] and Lü et al. [189] developed a self-healing, biocompatible and injectable dual cross-linked CS-based hydrogels for in vivo delivery of BMP-4. This hydrogel was crosslinked through both diels-alder (DA) and acylhydrazone bonds; and the authors used these bonding schemes to fine-tune various hydrogel properties such as rigidity and degradation. Through this sophisticated crosslinking scheme they were also able to manufacture a superior hydrogel, which could prevent excessive hydrogel swelling in vivo; and thereby prevent poor stem cell differentiation and tissue regeneration.[190] In both instances, histology staining's demonstrated new bone formation in the BMP-4 loaded hydrogel samples after 12 weeks, with controls primarily stimulating fibrous tissue growth. Additionally, initial sproutings of blood vessels were observed. In another noteworthy study, Kim et al. [181] evaluated the inclusion of UV-crosslinked methacrylated CS (MeCS) in PEGDA hydrogels at various concentrations in terms of their bone regenerative properties within the body (Figure 6). Specifically, these scaffolds were implanted in critical sized calvarial defects ( $4 \mathrm{~mm}$ diameter) in six-week-old female mice $(\mathrm{n}=4)$ for up-to eight weeks. Interestingly, scaffolds containing the highest concentration of CS induced the most effective bone formation evidenced by larger bone mineralization density. This was speculated to arise from the ability of the sulfate groups within CS to bind to calcium ions and facilitate the formation of fresh hydroxyapatite; one of the most important components of the mineral phase of bone. Additionally, Hematoxylin, Eosin and Masson's trichrome staining's also showed significant improvements in bone tissue formation with increasing CS concentration.

Although, a wide range of sulfated polysaccharides have been studied in the literature, these biomaterials are seldom employed in clinical treatments due to the lack of more standardized clinical studies.[191] Indeed, a number of important parameters such as the size of the bone defect, the place of the defect, the implanted cell type, and implantation time needs to be considered to fully unravel the bone tissue engineering potential of such scaffolds. Unfortunately, these parameters have not been studied enough to turn this promising strategy into a clinical therapy which can benefit the many sufferers of bone disorders.[191] Consequently, more in-depth in vivo 
studies are necessary to validate the efficiency of sulfated polysaccharides for bone tissue engineering, and to identify the best combination to use in the clinic.

\section{$3 \quad 3.2$ Cartilage}

The primary cause of cartilage damage within the body is due to osteoarthritis (OA) in articular cartilage. The clinical treatment for OA is currently suboptimal as the "state-of-the-art" surgical approaches are limited in terms of their efficacy and high invasiveness. First stage interventions include arthroscopy, which involves the flushing and removal of damaged cartilage and meniscus.[192] For more severe cases, the implantation of autologous osteochondral graft (mosaicplasty) into the defect site and surgical drilling into the subchondral bone (microfracturing) can be employed.[193] However, unfortunately both measures are controversial as they often result in fibrous cartilage rather than native articular cartilage.[194] For the most severe cases, extremely invasive and costly total knee replacements can be performed.[195] Notably, these measures are aimed at slowing the impact of OA without actively regenerating native cartilage.

Recently, techniques such as stem cell therapy have been used to regenerate cartilage tissue, by injecting regenerative cells into the damaged region.[43, 48, 174, 196] This technique is limited by low cell retention and a low cell viability, caused by the shear-forces that cells experience when passing through the thin injection needle. It also does not provide the cells with a 3D microenvironment to properly differentiate them into the required tissues. The usage of hydrogels can provide a mechanical shield during the needle-injection phase and provide a proper 3D microenvironment for guiding cells into the desired cell phenotypes in a post-injection scenario. Especially, sulfated hydrogels hold great promise in this respect, since they display high affinity towards important growth factors for cartilage regeneration; and in many ways resemble - CS - one of the most important components of the native cartilage ECM. Indeed, such biopolymers have recently been used to develop scaffolds with the capacity to deliver growth factors such as BMP-2 and TGF- $\beta 3$ in a sustainable manner to significantly improve the cellular performance of chondrocytes.[75, 76] In another related study by Han et al. [197] a mussel inspired CS-based hydrogel was created for enhanced adhesion between graft and native cartilage tissue (Figure 7). Specifically, the inclusion of CS promoted an upregulation of chondrogenic differentiation markers such as aggrecan and collagen II. The scaffolds were also evaluated in a full thickness defects (diameter: $3.5 \mathrm{~mm}$; thickness: $5 \mathrm{~mm})$ in the patella groves in the right legs of white rabbits $(\mathrm{n}=8)$. Following a three-month implantation period, the scaffolds showed significantly higher tissue formation in terms of Modified O'Driscoll and International Cartilage Repair Society grading scores.

The abovementioned studies on using sulfated polysaccharides for cartilage regeneration clearly demonstrate the great promise that they hold for the field of cartilage tissue engineering. Indeed, considering the importance of cell therapy in treating acute cartilage injuries, sulfated polysaccharides can be ideal scaffolding materials to support the chondrocytes temporarily until the implanted cells replace them by matrix components. Collectively, the use of such scaffolds is expected to reduce chondrocyte leakage from the transplant site, facilitate a more homogeneous chondrocyte distribution, and diminish graft hypertrophy.[198] Regardless, if these scaffolds were to be used in cartilage tissue engineering, we would need to consider important parameters such as lesion location and damage size, activity level and patient's age. These parameters are by many in the field considered the important parameters when it comes down to deciding which cartilage repair approaches to use 
and evaluating the treatment.[199] Finally, the biomaterials utilised in in vivo cartilage tissue engineering need to demonstrate appropriate biomechanical and biochemical cues without triggering immune responses. Therefore, biomaterials and cell therapy techniques should also be compared to 'gold standard' techniques such as microfracture and grafting in order to accurately gauge their efficacy in vivo. The continued investigations into the usage of sulfated polysaccharides as growth factor delivery vehicles is also needed to fully elucidate their potential as tissue engineering scaffolds for cartilage regeneration.

\subsection{Osteochondral}

Defects that impact both the articular cartilage and the underlying subchondral tissues are termed osteochondral defects. Such lesions are caused by tissue degradation from aging, sports injuries or severe cases of osteoarthritis. They typically result in joint instability, significant discomfort for the patient and loss of patient mobility. Much like cartilage, osteochondral defects can be treated through microfracturing, allografting and mosaicplasty, or even total knee replacements, however, all of these therapies unfortunately have similar issues as those briefly mentioned in the previous section.[200] The abovementioned tissue engineering approaches could remedy these shortcomings by recapitulating the highly hierarchal structure of osteochondral defects.

In this direction, Zhou et al. [201] recently combined silk fibroin with CS to develop a composite scaffold that could mend osteochondral defects in a rabbit animal model. Indeed, this composite material produced greater neo-tissue formation and improved structural restoration compared to the pristine silk scaffold at 6 and 12 weeks as evident from an International Cartilage Repair Society histological analysis (Figure 8). Additionally, when analysed in vitro, the composite scaffold was seen to maintain better chondrocyte morphology compared to the silk scaffold alone, in combination with a higher expression of SOX9, collagen II, aggrecan and lower expression of TNF- $\alpha 2$ (an important inflammation marker) (Figure 8). In a similar vein, Liao et al. [202] implanted a biomaterial composite consisting of methacrylated CS and poly(ethylene glycol) methyl ether- $\varepsilon$-caprolactoneacryloyl chloride (MPEG-PCL-AC) incorporated with graphene oxide, into full-thickness osteochondral defects (thickness: $3 \mathrm{~mm}$, diameter: $4 \mathrm{~mm}, \mathrm{n}=27$ ) in the hind limbs of rabbits. When combined with chondrocytes, the scaffold was seen to improve chondrocyte morphology, integration, and subchondral bone formation. Notably, this strategy could rapidly induce the formation of both new and thicker cartilage tissue as compared to a cell-free scaffold.

In another study Feng et al. [52] conjugated sulfate groups onto the backbone of methacrylated hyaluronic acid (MeHA) in order to deliver growth factors in a osteochondral rodent $(n=10)$ model in a controlled and sustainable manner (Figure 9). Typically, HA is degraded rapidly by hyaluronidases in vivo and lacks high protein binding affinity. They found that the introduction of sulfate groups reduced the degradation and deformation of hydrogel scaffolds and promoted cartilage matrix deposition, as indicated by immunohistochemical stainings of collagen II and CS, following 4 weeks in vivo studies. Additionally, the sulfated-HA in combination with hMSCs was capable of attracting and retaining supplemented TGF- $\beta 1$, and thereby promoting chondrogenesis and suppressing hypertrophy. Overall, the paper by Feng et al. [52] demonstrates that sulfated HA hydrogels enable the generation of high quality neocartilage via intra-articular injection. Another noteworthy study used a heparin immobilised polycaprolactone (PCL)/Pluronic F127 scaffold combined with TGF- $\beta 2$ and BMP-7 to facilitate even more cartilage tissue formation as compared to PCL/Pluronic scaffolds alone. However, no significant histological 
differences following implantation into large (diameter $=6 \mathrm{~mm}$, depth $=3 \mathrm{~mm})$ distal femur defects in rabbits $(\mathrm{n}=$

12) was seen in this study.[203] Finally, Re'em et al. [204] recently created a bilayer scaffold with alginate-sulfate incorporating both TGF- $\beta 2$ and BMP-4. This scaffold was subsequently implanted into subchondral defects (diameter $=3 \mathrm{~mm}$, depth $=3 \mathrm{~mm}$ ) in the femur of rabbits. Encapsulated hMSC's were successfully differentiated into both osteoblasts and chondrocytes at respective layers over 4 weeks, confirming the controlled release of the growth factors. Additionally, the cartilage-bone interface formation remained the same in hMSC incorporated scaffolds, indicating that native cells were able to migrate into the scaffolds and sense the biological cues spatially present in there, and respond accordingly by differentiating to the appropriate cellular lineage.

History has shown that applying promising laboratory strategies to animal models is not always as successful. Even a rudimentary understanding, through the use of pilot studies, of the in vivo efficacy of such techniques can create a much more efficient process for producing novel, viable tissue engineering solutions. For these reasons, sulfated-scaffolds for osteochondral tissue engineering are also beginning to be translated into in vivo environments. Most often, these materials are used in composites to capitalise upon the benefits of multiple materials and to develop the hierarchical scaffolding architecture needed for optimal ostechondral repair. To this end, the effects of growth factor delivery and improved cellular performance observed in in vitro studies appear to translate into in vivo outcomes. Additionally, the studies reviewed here indicate that sulfated polysaccharide do not elicit any significant inflammatory responses when implanted in vivo, confirming that they indeed are suitable biomaterials for osteochondral tissue engineering.

\section{Conclusion and future directions}

Tissue engineering has shown tremendous potential in several facets of biomedicine, particularly in skeletal tissue engineering. With the ongoing development of novel sulfated biomaterials along with sophisticated in vitro culturing systems tissue engineering will enhance our capacity to recapitulate bone and cartilage regeneration through the sustained delivery of relevant growth factors. Overwhelmingly, the most commonly studied and successful naturally sulfated biomaterials include CS and heparan sulfate and its analogues. The benefits that these naturally sulfated ECM components provide can be chemically incorporated into non-sulfated biomaterials. Specifically, HA and chitosan sulfation allows for the controlled binding and release of growth factors in a localised environment. The use of composite materials in tissue engineering is omnipresent and can capitalise upon the benefits of multiple materials. These four materials, CS, Hep/HS, HA and chitosan, can be easily utilised in a composite system, where the scaffold can provide cells with controlled, prolonged and protected growth factor delivery. Though, the translational capacity of animal-derived sulfated biomaterials is limited in vivo due to immunogenicity, further exploration into plant-derived substrates could be a worthy endeavour. Intriguingly, as these materials don't have specific enzymes for degradation their use could potentially extend growth factor delivery beyond the body's native capacity. Many areas within the vibrant field of tissue engineering could readily benefit from the utilization of sulfated biomaterials as a vehicle for providing growth factors to the target tissues to elicit improved cellular performance both in vitro and in vivo.

\section{Acknowledgements}


ADP would like to acknowledge the Danish Council for Independent Research (Technology and Production Sciences, 5054-00142B), Gigtforeningen (R139-A3864) and the Villum Foundation (10103). This work is also part of the VIDI research programme with project number R0004387, which is (partly) financed by the Netherlands Organisation for Scientific Research (NWO). JF would also like to acknowledge the funding from the Australian Research Council under the Discovery Early Career Researcher Award (J.F., grant no. DE130100517).

\section{References}

1. Vos, T., A.A. Abajobir, K.H. Abate, C. Abbafati, K.M. Abbas, F. Abd-Allah, R.S. Abdulkader, A.M. Abdulle, T.A. Abebo, and S.F. Abera, Global, regional, and national incidence, prevalence, and years lived with disability for 328 diseases and injuries for 195 countries, 1990-2016: a systematic analysis for the Global Burden of Disease Study 2016. The Lancet, 2017. 390(10100): p. 1211-1259.

2. Abbah, S.A., L.M. Delgado, A. Azeem, K. Fuller, N. Shologu, M. Keeney, M.J. Biggs, A. Pandit, and D.I. Zeugolis, Harnessing hierarchical nano-and micro-fabrication technologies for musculoskeletal tissue engineering. Advanced healthcare materials, 2015. 4(16): p. 24882499.

3. Cross, L.M., A. Thakur, N.A. Jalili, M. Detamore, and A.K. Gaharwar, Nanoengineered biomaterials for repair and regeneration of orthopedic tissue interfaces. Acta biomaterialia, 2016. 42: p. 2-17.

4. Elisseeff, J., C. Puleo, F. Yang, and B. Sharma, Advances in skeletal tissue engineering with hydrogels. Orthodontics \& craniofacial research, 2005. 8(3): p. 150-161.

5. Hunziker, E., Articular cartilage repair: basic science and clinical progress. A review of the current status and prospects. Osteoarthritis and cartilage, 2002. 10(6): p. 432-463.

6. Tatara, A.M. and A.G. Mikos, Tissue engineering in orthopaedics. The Journal of bone and joint surgery. American volume, 2016. 98(13): p. 1132.

7. Nukavarapu, S.P. and D.L. Dorcemus, Osteochondral tissue engineering: Current strategies and challenges. Biotechnology Advances, 2013. 31(5): p. 706-721.

8. Pina, S., J.M. Oliveira, and R.L. Reis, Natural-based nanocomposites for bone tissue engineering and regenerative medicine: A review. Advanced Materials, 2015. 27(7): p. 11431169.

9. Wu, S., X. Liu, K.W.K. Yeung, C. Liu, and X. Yang, Biomimetic porous scaffolds for bone tissue engineering. Materials Science and Engineering: R: Reports, 2014. 80: p. 1-36.

10. Guarino, V., F. Causa, and L. Ambrosio, Bioactive scaffolds for bone and ligament tissue. Expert review of medical devices, 2007. 4(3): p. 405-418.

11. Kim, T.G., H. Shin, and D.W. Lim, Biomimetic scaffolds for tissue engineering. Advanced Functional Materials, 2012. 22(12): p. 2446-2468.

12. Place, E.S., N.D. Evans, and M.M. Stevens, Complexity in biomaterials for tissue engineering. Nature materials, 2009. 8(6): p. 457.

13. Park, H.-J., S.J. Yu, K. Yang, Y. Jin, A.-N. Cho, J. Kim, B. Lee, H.S. Yang, S.G. Im, and S.-W. Cho, based bioactive scaffolds for stem cell-mediated bone tissue engineering. Biomaterials, 2014. 35(37): p. 9811-9823. 
14. Mehdi, M., T. Ashish, P.C. Pablo, T. Sepehr, A. Ayyoob, N. Mehdi, and D.-P. Alireza, Nanoreinforced Hydrogels for Tissue Engineering: Biomaterials that are Compatible with Load-Bearing and Electroactive Tissues. Advanced Materials, 2017. 29(8): p. 1603612.

15. Lee, K., E.A. Silva, and D.J. Mooney, Growth factor delivery-based tissue engineering: general approaches and a review of recent developments. Journal of the Royal Society Interface, 2011. 8(55): p. 153-170.

16. Rahmany, M.B. and M. Van Dyke, Biomimetic approaches to modulate cellular adhesion in biomaterials: A review. Acta biomaterialia, 2013. 9(3): p. 5431-5437.

17. LeBaron, R.G. and K.A. Athanasiou, Extracellular matrix cell adhesion peptides: functional applications in orthopedic materials. Tissue engineering, 2000. 6(2): p. 85-103.

18. Padmanabhan, J. and T.R. Kyriakides, Nanomaterials, inflammation, and tissue engineering. Wiley Interdisciplinary Reviews: Nanomedicine and Nanobiotechnology, 2015. 7(3): p. 355370.

19. Harrison, B.S. and A. Atala, Carbon nanotube applications for tissue engineering. Biomaterials, 2007. 28(2): p. 344-353.

20. Chen, F.-M., M. Zhang, and Z.-F. Wu, Toward delivery of multiple growth factors in tissue engineering. Biomaterials, 2010. 31(24): p. 6279-6308.

21. Martino, M.M., F. Tortelli, M. Mochizuki, S. Traub, D. Ben-David, G.A. Kuhn, R. Müller, E. Livne, S.A. Eming, and J.A. Hubbell, Engineering the Growth Factor Microenvironment with Fibronectin Domains to Promote Wound and Bone Tissue Healing. Science Translational Medicine, 2011. 3(100): p. 100ra89-100ra89.

22. Feng, L., Y. Li, W. Zeng, B. Xia, D. Zhou, and J. Zhou, Enhancing effects of basic fibroblast growth factor and fibronectin on osteoblast adhesion to bone scaffolds for bone tissue engineering through extracellular matrix-integrin pathway. Experimental and therapeutic medicine, 2017. 14(6): p. 6087-6092.

23. Rammelt, S., T. Illert, S. Bierbaum, D. Scharnweber, H. Zwipp, and W. Schneiders, Coating of titanium implants with collagen, RGD peptide and chondroitin sulfate. Biomaterials, 2006. 27(32): p. 5561-5571.

24. Bayless, K.J. and G.E. Davis, Identification of dual alpha 4beta1 integrin binding sites within a 38 amino acid domain in the $\mathrm{N}$-terminal thrombin fragment of human osteopontin. J Biol Chem, 2001. 276(16): p. 13483-9.

25. Vogel, B.E., S.-J. Lee, A. Hildebrand, W. Craig, M.D. Pierschbacher, F. Wong-Staal, and E. Ruoslahti, A novel integrin specificity exemplified by binding of the alpha $v$ beta 5 integrin to the basic domain of the HIV Tat protein and vitronectin. The Journal of Cell Biology, 1993. 121(2): p. 461-468.

26. Noori, A., S.J. Ashrafi, R. Vaez-Ghaemi, A. Hatamian-Zaremi, and T.J. Webster, A review of fibrin and fibrin composites for bone tissue engineering. International journal of nanomedicine, 2017. 12: p. 4937.

27. Bellis, S.L., Advantages of RGD peptides for directing cell association with biomaterials. Biomaterials, 2011. 32(18): p. 4205-4210.

28. Huettner, N., T.R. Dargaville, and A. Forget, Discovering Cell-Adhesion Peptides in Tissue Engineering: Beyond RGD. Trends in Biotechnology, 2018. 36(4): p. 372-383.

29. Jensen, T., A. Dolatshahi-Pirouz, M. Foss, J. Baas, J. Lovmand, M. Duch, F.S. Pedersen, M. Kassem, C. Bünger, and K. Søballe, Interaction of human mesenchymal stem cells with osteopontin coated hydroxyapatite surfaces. Colloids and Surfaces B: Biointerfaces, 2010. 75(1): p. 186-193.

30. Jensen, T., J. Baas, A. Dolathshahi-Pirouz, T. Jacobsen, G. Singh, J.V. Nygaard, M. Foss, J. Bechtold, C. Bünger, and F. Besenbacher, Osteopontin functionalization of hydroxyapatite nanoparticles in a PDLLA matrix promotes bone formation. Journal of Biomedical Materials Research Part A, 2011. 99(1): p. 94-101. 
31. Senni, K., J. Pereira, F. Gueniche, C. Delbarre-Ladrat, C. Sinquin, J. Ratiskol, G. Godeau, A.-M. Fischer, D. Helley, and S. Colliec-Jouault, Marine polysaccharides: A source of bioactive molecules for cell therapy and tissue engineering. Marine Drugs, 2011. 9(9): p. 1664-1681.

32. Xian, X., S. Gopal, and J.R. Couchman, Syndecans as receptors and organizers of the extracellular matrix. Cell and tissue research, 2010. 339(1): p. 31.

33. Farrugia, B.L., M.S. Lord, J. Melrose, and J.M. Whitelock, Can we produce heparin/heparan sulfate biomimetics using "mother-nature" as the gold standard? Molecules, 2015. 20(3): p. 4254-4276.

34. Mizumoto, S., D. Fongmoon, and K. Sugahara, Interaction of chondroitin sulfate and dermatan sulfate from various biological sources with heparin-binding growth factors and cytokines. Glycoconjugate journal, 2013. 30(6): p. 619-632.

35. Takada, T., T. Katagiri, M. Ifuku, N. Morimura, M. Kobayashi, K. Hasegawa, A. Ogamo, and R. Kamijo, Sulfated polysaccharides enhance the biological activities of bone morphogenetic proteins. Journal of Biological Chemistry, 2003.

36. Hintze, V., S.A. Samsonov, M. Anselmi, S. Moeller, J. Becher, M. Schnabelrauch, D. Scharnweber, and M.T. Pisabarro, Sulfated glycosaminoglycans exploit the conformational plasticity of bone morphogenetic protein-2 (BMP-2) and alter the interaction profile with its receptor. Biomacromolecules, 2014. 15(8): p. 3083-3092.

37. Silva, T.H., A. Alves, E.G. Popa, L.L. Reys, M.E. Gomes, R.A. Sousa, S.S. Silva, J.F. Mano, and R.L. Reis, Marine algae sulfated polysaccharides for tissue engineering and drug delivery approaches. Biomatter, 2012. 2(4): p. 278-289.

38. Salbach, J., S. Kliemt, M. Rauner, T.D. Rachner, C. Goettsch, S. Kalkhof, M. von Bergen, S. Möller, M. Schnabelrauch, V. Hintze, D. Scharnweber, and L.C. Hofbauer, The effect of the degree of sulfation of glycosaminoglycans on osteoclast function and signaling pathways. Biomaterials, 2012. 33(33): p. 8418-8429.

39. Picke, A.-K., J. Salbach-Hirsch, V. Hintze, S. Rother, M. Rauner, C. Kascholke, S. Möller, R. Bernhardt, S. Rammelt, M.T. Pisabarro, G. Ruiz-Gómez, M. Schnabelrauch, M. SchulzSiegmund, M.C. Hacker, D. Scharnweber, C. Hofbauer, and L.C. Hofbauer, Sulfated hyaluronan improves bone regeneration of diabetic rats by binding sclerostin and enhancing osteoblast function. Biomaterials, 2016. 96: p. 11-23.

40. Juliane, S.-H., Z. Nicole, T. Sylvia, M. Stephanie, S. Matthias, H. Vera, S. Dieter, R. Martina, and H.L. C., Sulfated Glycosaminoglycans Support Osteoblast Functions and Concurrently Suppress Osteoclasts. Journal of Cellular Biochemistry, 2014. 115(6): p. 1101-1111.

41. Hempel, U., S. Möller, C. Noack, V. Hintze, D. Scharnweber, M. Schnabelrauch, and P. Dieter, Sulfated hyaluronan/collagen I matrices enhance the osteogenic differentiation of human mesenchymal stromal cells in vitro even in the absence of dexamethasone. Acta Biomaterialia, 2012. 8(11): p. 4064-4072.

42. Kawamura, D., T. Funakoshi, S. Mizumoto, K. Sugahara, and N. Iwasaki, Sulfation patterns of exogenous chondroitin sulfate affect chondrogenic differentiation of ATDC5 cells. Journal of Orthopaedic Science, 2014. 19(6): p. 1028-1035.

43. Radhakrishnan, J., A. Subramanian, U.M. Krishnan, and S. Sethuraman, Injectable and 3D bioprinted polysaccharide hydrogels: from cartilage to osteochondral tissue engineering. Biomacromolecules, 2016. 18(1): p. 1-26.

44. Park, J., S.J. Lee, H. Lee, S.A. Park, and J.Y. Lee, Three dimensional cell printing with sulfated alginate for improved bone morphogenetic protein-2 delivery and osteogenesis in bone tissue engineering. Carbohydrate Polymers, 2018. 196: p. 217-224.

45. Sawatjui, N., T. Damrongrungruang, W. Leeanansaksiri, P. Jearanaikoon, S. Hongeng, and T. Limpaiboon, Silk fibroin/gelatin-chondroitin sulfate-hyaluronic acid effectively enhances in vitro chondrogenesis of bone marrow mesenchymal stem cells. Materials Science and Engineering: C, 2015. 52: p. 90-96. 
46. Rodrigues, M.N., M.B. Oliveira, R.R. Costa, and J.o.F. Mano, Chitosan/chondroitin sulfate membranes produced by polyelectrolyte complexation for cartilage engineering. Biomacromolecules, 2016. 17(6): p. 2178-2188.

47. Abbadessa, A., V.H. Mouser, M.M. Blokzijl, D. Gawlitta, W.J. Dhert, W.E. Hennink, J. Malda, and T. Vermonden, $A$ synthetic thermosensitive hydrogel for cartilage bioprinting and its biofunctionalization with polysaccharides. Biomacromolecules, 2016. 17(6): p. 2137-2147.

48. Chen, F., S. Yu, B. Liu, Y. Ni, C. Yu, Y. Su, X. Zhu, X. Yu, Y. Zhou, and D. Yan, An injectable enzymatically crosslinked carboxymethylated pullulan/chondroitin sulfate hydrogel for cartilage tissue engineering. Scientific reports, 2016. 6: p. 20014.

49. Puvaneswary, S., H.B. Raghavendran, S. Talebian, M.R. Murali, S.A. Mahmod, S. Singh, and T. Kamarul, Incorporation of fucoidan in B-tricalcium phosphate-chitosan scaffold prompts the differentiation of human bone marrow stromal cells into osteogenic lineage. Scientific Reports, 2016. 6: p. 24202.

50. Goonoo, N., B. Khanbabaee, M. Steuber, A. Bhaw-Luximon, U. Jonas, U. Pietsch, D. Jhurry, and $\mathrm{H}$. Schönherr, $\mathrm{k}$-Carrageenan Enhances the Biomineralization and Osteogenic Differentiation of Electrospun Polyhydroxybutyrate and Polyhydroxybutyrate Valerate Fibers. Biomacromolecules, 2017. 18(5): p. 1563-1573.

51. Liang, X., X. Wang, Q. Xu, Y. Lu, Y. Zhang, H. Xia, A. Lu, and L. Zhang, Rubbery Chitosan/Carrageenan Hydrogels Constructed through an Electroneutrality System and Their Potential Application as Cartilage Scaffolds. Biomacromolecules, 2018. 19(2): p. 340-352.

52. Feng, Q., S. Lin, K. Zhang, C. Dong, T. Wu, H. Huang, X. Yan, L. Zhang, G. Li, and L. Bian, Sulfated hyaluronic acid hydrogels with retarded degradation and enhanced growth factor retention promote hMSC chondrogenesis and articular cartilage integrity with reduced hypertrophy. Acta biomaterialia, 2017. 53: p. 329-342.

53. Steinmetz, N.J., E.A. Aisenbrey, K.K. Westbrook, H.J. Qi, and S.J. Bryant, Mechanical loading regulates human MSC differentiation in a multi-layer hydrogel for osteochondral tissue engineering. Acta biomaterialia, 2015. 21: p. 142-153.

54. Silva, T.H. and R. Reis, Drug delivery systems and cartilage tissue engineering scaffolding using marine-derived products, in Functional Marine Biomaterials. 2015, Elsevier. p. 123-136.

55. Venkatesan, J. and S.K. Kim, Marine Algae Derived Polysaccharides for Bone Tissue Regeneration. Marine Algae Extracts: Processes, Products, and Applications, 2015: p. 509522.

56. Esko, J.D., K. Kimata, and U. Lindahl, Proteoglycans and sulfated glycosaminoglycans. 2009.

57. Lima, M., T. Rudd, and E. Yates, New applications of heparin and other glycosaminoglycans. Molecules, 2017. 22(5): p. 749.

58. Minsky, B.B., P.L. Dubin, and I.A. Kaltashov, Electrostatic Forces as Dominant Interactions Between Proteins and Polyanions: an ESI MS Study of Fibroblast Growth Factor Binding to Heparin Oligomers. Journal of The American Society for Mass Spectrometry, 2017. 28(4): p. 758-767.

59. Chiodelli, P., A. Bugatti, C. Urbinati, and M. Rusnati, Heparin/Heparan sulfate proteoglycans glycomic interactome in angiogenesis: biological implications and therapeutical use. Molecules, 2015. 20(4): p. 6342-6388.

60. Weiss, R.J., J.D. Esko, and Y. Tor, Targeting heparin and heparan sulfate protein interactions. Organic \& biomolecular chemistry, 2017. 15(27): p. 5656-5668.

61. Kreuger, J., D. Spillmann, J.-p. Li, and U. Lindahl, Interactions between heparan sulfate and proteins: the concept of specificity. The Journal of cell biology, 2006. 174(3): p. 323-327.

62. Rabenstein, D.L., Heparin and heparan sulfate: structure and function. Natural product reports, 2002. 19(3): p. 312-331.

63. Shriver, Z., I. Capila, G. Venkataraman, and R. Sasisekharan, Heparin and heparan sulfate: analyzing structure and microheterogeneity, in Heparin-A Century of Progress. 2012, Springer. p. 159-176. 
64. Olczyk, P., Ł. Mencner, and K. Komosinska-Vassev, Diverse roles of heparan sulfate and heparin in wound repair. BioMed research international, 2015. 2015.

65. Rapraeger, A.C., A. Krufka, and B.B. Olwin, Requirement of heparan sulfate for bFGFmediated fibroblast growth and myoblast differentiation. Science, 1991. 252(5013): p. 17051708.

66. Gray, E., J. Hogwood, and B. Mulloy, The anticoagulant and antithrombotic mechanisms of heparin. Handb Exp Pharmacol, 2012(207): p. 43-61.

67. Jin, L., J.P. Abrahams, R. Skinner, M. Petitou, R.N. Pike, and R.W. Carrell, The anticoagulant activation of antithrombin by heparin. Proceedings of the National Academy of Sciences, 1997. 94(26): p. 14683-14688.

68. Zhao, B., T. Katagiri, H. Toyoda, T. Takada, T. Yanai, T. Fukuda, U.I. Chung, T. Koike, K. Takaoka, and R. Kamijo, Heparin potentiates the in vivo ectopic bone formation induced by bone morphogenetic protein-2. J Biol Chem, 2006. 281(32): p. 23246-53.

69. Lee, S.S., B.J. Huang, S.R. Kaltz, S. Sur, C.J. Newcomb, S.R. Stock, R.N. Shah, and S.I. Stupp, Bone regeneration with low dose BMP-2 amplified by biomimetic supramolecular nanofibers within collagen scaffolds. Biomaterials, 2013. 34(2): p. 452-459.

70. Takada, T., T. Katagiri, M. Ifuku, N. Morimura, M. Kobayashi, K. Hasegawa, A. Ogamo, and R. Kamijo, Sulfated polysaccharides enhance the biological activities of bone morphogenetic proteins. J Biol Chem, 2003. 278(44): p. 43229-35.

71. Hettiaratchi, M.H., T. Miller, J.S. Temenoff, R.E. Guldberg, and T.C. McDevitt, Heparin microparticle effects on presentation and bioactivity of bone morphogenetic protein-2. Biomaterials, 2014. 35(25): p. 7228-7238.

72. Kim, S.E., Y.-P. Yun, K.-S. Shim, K. Park, S.-W. Choi, D.H. Shin, and D.H. Suh, Fabrication of a BMP-2-immobilized porous microsphere modified by heparin for bone tissue engineering. Colloids and Surfaces B: Biointerfaces, 2015. 134: p. 453-460.

73. Bramono, D.S., S. Murali, B. Rai, L. Ling, W.T. Poh, Z.X. Lim, G.S. Stein, V. Nurcombe, A.J. Van Wijnen, and S.M. Cool, Bone marrow-derived heparan sulfate potentiates the osteogenic activity of bone morphogenetic protein-2 (BMP-2). Bone, 2012. 50(4): p. 954-964.

74. Esko, J.D. and S.B. Selleck, Order out of chaos: assembly of ligand binding sites in heparan sulfate. Annual review of biochemistry, 2002. 71(1): p. 435-471.

75. Chen, J., Y. Wang, C. Chen, C. Lian, T. Zhou, B. Gao, Z. Wu, and C. Xu, Exogenous heparan sulfate enhances the TGF-63-induced chondrogenesis in human mesenchymal stem cells by activating TGF-6/Smad signaling. Stem cells international, 2016. 2016.

76. Fernández-Muiños, T., L. Recha-Sancho, P. López-Chicón, C. Castells-Sala, A. Mata, and C.E. Semino, Bimolecular based heparin and self-assembling hydrogel for tissue engineering applications. Acta biomaterialia, 2015. 16: p. 35-48.

77. Tellado, S.F., S. Chiera, W. Bonani, P.S. Poh, C. Migliaresi, A. Motta, E.R. Balmayor, and M. van Griensven, Heparin functionalization increases retention of TGF-62 and GDF5 on biphasic silk fibroin scaffolds for tendon/ligament-to-bone tissue engineering. Acta biomaterialia, 2018. 72: p. 150-166.

78. Sugahara, K., T. Mikami, T. Uyama, S. Mizuguchi, K. Nomura, and H. Kitagawa, Recent advances in the structural biology of chondroitin sulfate and dermatan sulfate. Current opinion in structural biology, 2003. 13(5): p. 612-620.

79. Kiani, C., C. Liwen, Y.J. Wu, J.Y. Albert, and B.Y. Burton, Structure and function of aggrecan. Cell research, 2002. 12(1): p. 19.

80. Varghese, S., N.S. Hwang, A.C. Canver, P. Theprungsirikul, D.W. Lin, and J. Elisseeff, Chondroitin sulfate based niches for chondrogenic differentiation of mesenchymal stem cells. Matrix Biology, 2008. 27(1): p. 12-21.

81. Farrugia, B.L., M. Lord, J. Whitelock, and J. Melrose, Harnessing chondroitin sulphate in composite scaffolds to direct progenitor and stem cell function for tissue repair. Biomaterials science, 2018. 6(5): p. 947-957. 
82. Levett, P.A., F.P. Melchels, K. Schrobback, D.W. Hutmacher, J. Malda, and T.J. Klein, $A$ biomimetic extracellular matrix for cartilage tissue engineering centered on photocurable gelatin, hyaluronic acid and chondroitin sulfate. Acta biomaterialia, 2014. 10(1): p. 214-223.

83. Ponta, H., L. Sherman, and P.A. Herrlich, CD44: from adhesion molecules to signalling regulators. Nature reviews Molecular cell biology, 2003. 4(1): p. 33.

84. Zhu, M., Q. Feng, Y. Sun, G. Li, and L. Bian, Effect of cartilaginous matrix components on the chondrogenesis and hypertrophy of mesenchymal stem cells in hyaluronic acid hydrogels. Journal of Biomedical Materials Research Part B: Applied Biomaterials, 2017. 105(8): p. 2292-2300.

85. Costantini, M., J. Idaszek, K. Szöke, J. Jaroszewicz, M. Dentini, A. Barbetta, J.E. Brinchmann, and W. Święszkowski, 3D bioprinting of BM-MSCs-loaded ECM biomimetic hydrogels for in vitro neocartilage formation. Biofabrication, 2016. 8(3): p. 035002.

86. Park, J.S., J.S. Chu, A.D. Tsou, R. Diop, Z. Tang, A. Wang, and S. Li, The effect of matrix stiffness on the differentiation of mesenchymal stem cells in response to TGF-B. Biomaterials, 2011. 32(16): p. 3921-3930.

87. Engler, A.J., S. Sen, H.L. Sweeney, and D.E. Discher, Matrix elasticity directs stem cell lineage specification. Cell, 2006. 126(4): p. 677-689.

88. Manivasagan, P. and J. Oh, Marine polysaccharide-based nanomaterials as a novel source of nanobiotechnological applications. International Journal of Biological Macromolecules, 2016. 82: p. 315-327.

89. Lim, J.J. and J.S. Temenoff, The effect of desulfation of chondroitin sulfate on interactions with positively charged growth factors and upregulation of cartilaginous markers in encapsulated MSCs. Biomaterials, 2013. 34(21): p. 5007-5018.

90. Hayami, J.W., S.D. Waldman, and B.G. Amsden, Chondrocyte Generation of Cartilage-Like Tissue Following Photoencapsulation in Methacrylated Polysaccharide Solution Blends. Macromolecular bioscience, 2016. 16(7): p. 1083-1095.

91. Recha-Sancho, L. and C.E. Semino, Chondroitin sulfate-and decorin-based self-assembling scaffolds for cartilage tissue engineering. PloS one, 2016. 11(6): p. e0157603.

92. Nair, M.B., G. Baranwal, P. Vijayan, K.S. Keyan, and R. Jayakumar, Composite hydrogel of chitosan-poly (hydroxybutyrate-co-valerate) with chondroitin sulfate nanoparticles for nucleus pulposus tissue engineering. Colloids and Surfaces B: Biointerfaces, 2015. 136: p. 8492.

93. Huang, Z., P. Nooeaid, B. Kohl, J.A. Roether, D.W. Schubert, C. Meier, A.R. Boccaccini, O. Godkin, W. Ertel, and S. Arens, Chondrogenesis of human bone marrow mesenchymal stromal cells in highly porous alginate-foams supplemented with chondroitin sulfate. Materials Science and Engineering: C, 2015. 50: p. 160-172.

94. Mathews, S., S.A. Mathew, P.K. Gupta, R. Bhonde, and S. Totey, Glycosaminoglycans enhance osteoblast differentiation of bone marrow derived human mesenchymal stem cells. Journal of tissue engineering and regenerative medicine, 2014. 8(2): p. 143-152.

95. Vandrovcová, M., T. Douglas, D. Hauk, B. Grössner-Schreiber, J. Wiltfang, L. Bacakova, and P.H. Warnke, Influence of collagen and chondroitin sulfate (CS) coatings on poly-(lactide-coglycolide)(PLGA) on MG 63 osteoblast-like cells. Physiological research, 2011. 60(5): p. 797.

96. Douglas, T., S. Heinemann, C. Mietrach, U. Hempel, S. Bierbaum, D. Scharnweber, and H. Worch, Interactions of Collagen Types I and II with Chondroitin Sulfates A-C and Their Effect on Osteoblast Adhesion. Biomacromolecules, 2007. 8(4): p. 1085-1092.

97. Dudeck, J., S. Rehberg, R. Bernhardt, W. Schneiders, O. Zierau, M. Inderchand, J. Goebbels, G. Vollmer, P. Fratzl, and D. Scharnweber, Increased bone remodelling around titanium implants coated with chondroitin sulfate in ovariectomized rats. Acta biomaterialia, 2014. 10(6): p. 2855-2865. 
98. Rees, S.G., D.T.H. Wassell, and G. Embery, Interaction of glucuronic acid and iduronic acidrich glycosaminoglycans and their modified forms with hydroxyapatite. Biomaterials, 2002. 23(2): p. 481-489.

99. Andreakis, N. and B. Schaffelke, Invasive marine seaweeds: pest or prize?, in Seaweed biology. 2012, Springer. p. 235-262.

100. Wijesinghe, W. and Y.-J. Jeon, Biological activities and potential industrial applications of fucose rich sulfated polysaccharides and fucoidans isolated from brown seaweeds: A review. Carbohydrate Polymers, 2012. 88(1): p. 13-20.

101. Lahaye, M., E.A.-C. Cimadevilla, R. Kuhlenkamp, B. Quemener, V. Lognoné, and P. Dion, Chemical composition and 13C NMR spectroscopic characterisation of ulvans from Ulva (Ulvales, Chlorophyta). Journal of Applied Phycology, 1999. 11(1): p. 1.

102. Popa, E.G., S.G. Caridade, J.F. Mano, R.L. Reis, and M.E. Gomes, Chondrogenic potential of injectable $\mathrm{k}$-carrageenan hydrogel with encapsulated adipose stem cells for cartilage tissueengineering applications. Journal of tissue engineering and regenerative medicine, 2015. 9(5): p. 550-563.

103. Thakur, A., M.K. Jaiswal, C.W. Peak, J.K. Carrow, J. Gentry, A. Dolatshahi-Pirouz, and A.K. Gaharwar, Injectable shear-thinning nanoengineered hydrogels for stem cell delivery. Nanoscale, 2016. 8(24): p. 12362-12372.

104. Pereira, R.C., M. Scaranari, P. Castagnola, M. Grandizio, H.S. Azevedo, R. Reis, R. Cancedda, and C. Gentili, Novel injectable gel (system) as a vehicle for human articular chondrocytes in cartilage tissue regeneration. Journal of tissue engineering and regenerative medicine, 2009. 3(2): p. 97-106.

105. Feng, W., S. Feng, K. Tang, X. He, A. Jing, and G. Liang, A novel composite of collagenhydroxyapatite/kappa-carrageenan. Journal of Alloys and Compounds, 2017. 693: p. 482489.

106. Oliveira, S.M., R.L. Reis, and J.o.F. Mano, Assembling human platelet lysate into multiscale 3D scaffolds for bone tissue engineering. ACS Biomaterials Science \& Engineering, 2014. 1(1): p. 2-6.

107. Zhang, Y., L. Ye, J. Cui, B. Yang, H. Sun, J. Li, and F. Yao, A biomimetic poly (vinyl alcohol)carrageenan composite scaffold with oriented microarchitecture. ACS Biomaterials Science \& Engineering, 2016. 2(4): p. 544-557.

108. Mihaila, S.M., E.G. Popa, R.L. Reis, A.P. Marques, and M.E. Gomes, Fabrication of endothelial cell-laden carrageenan microfibers for microvascularized bone tissue engineering applications. Biomacromolecules, 2014. 15(8): p. 2849-2860.

109. Popa, E., R. Reis, and M. Gomes, Chondrogenic phenotype of different cells encapsulated in $\kappa$-carrageenan hydrogels for cartilage regeneration strategies. Biotechnology and applied biochemistry, 2012. 59(2): p. 132-141.

110. Liu, H., J. Cheng, F. Chen, F. Hou, D. Bai, P. Xi, and Z. Zeng, Biomimetic and cell-mediated mineralization of hydroxyapatite by carrageenan functionalized graphene oxide. ACS applied materials \& interfaces, 2014. 6(5): p. 3132-3140.

111. Oliveira, S.M., T.H. Silva, R.L. Reis, and J.F. Mano, Nanocoatings containing sulfated polysaccharides prepared by layer-by-layer assembly as models to study cell-material interactions. Journal of Materials Chemistry B, 2013. 1(35): p. 4406-4418.

112. Li, J., B. Yang, Y. Qian, Q. Wang, R. Han, T. Hao, Y. Shu, Y. Zhang, F. Yao, and C. Wang, lotacarrageenan/chitosan/gelatin scaffold for the osteogenic differentiation of adipose-derived MSCs in vitro. Journal of Biomedical Materials Research Part B: Applied Biomaterials, 2015. 103(7): p. 1498-1510.

113. Klokkevold, P.R., L. Vandemark, E.B. Kenney, and G.W. Bernard, Osteogenesis enhanced by chitosan (poly-N-acetyl glucosaminoglycan) in vitro. Journal of periodontology, 1996. 67(11): p. $1170-1175$. 
114. Rocha, P.M., V.E. Santo, M.E. Gomes, R.L. Reis, and J.F. Mano, Encapsulation of adiposederived stem cells and transforming growth factor-61 in carrageenan-based hydrogels for cartilage tissue engineering. Journal of Bioactive and Compatible Polymers, 2011. 26(5): p. 493-507.

115. Li, B., F. Lu, X. Wei, and R. Zhao, Fucoidan: structure and bioactivity. Molecules, 2008. 13(8): p. 1671-1695.

116. O'Leary, R., M. Rerek, and E.J. Wood, Fucoidan modulates the effect of transforming growth factor (TGF)-61 on fibroblast proliferation and wound repopulation in in vitro models of dermal wound repair. Biological and Pharmaceutical Bulletin, 2004. 27(2): p. 266-270.

117. Puvaneswary, S., S. Talebian, H.B. Raghavendran, M.R. Murali, M. Mehrali, A.M. Afifi, N.H.B.A. Kasim, and T. Kamarul, Fabrication and in vitro biological activity of BTCP-ChitosanFucoidan composite for bone tissue engineering. Carbohydrate polymers, 2015. 134: p. 799807.

118. Discher, D.E., D.J. Mooney, and P.W. Zandstra, Growth factors, matrices, and forces combine and control stem cells. Science, 2009. 324(5935): p. 1673-1677.

119. Karunanithi, P., M.R. Murali, S. Samuel, H.R.B. Raghavendran, A.A. Abbas, and T. Kamarul, Three dimensional alginate-fucoidan composite hydrogel augments the chondrogenic differentiation of mesenchymal stromal cells. Carbohydrate polymers, 2016. 147: p. 294-303.

120. Brading, J.W., M.M. Georg-Plant, and D.M. Hardy, The polysaccharide from the alga Ulva lactuca. Purification, hydrolysis, and methylation of the polysaccharide. Journal of the Chemical Society (Resumed), 1954: p. 319-324.

121. Chiellini, F. and A. Morelli, Ulvan: a versatile platform of biomaterials from renewable resources, in Biomaterials-Physics and Chemistry. 2011, InTech.

122. Dash, M., S.K. Samal, C. Bartoli, A. Morelli, P.F. Smet, P. Dubruel, and F. Chiellini, Biofunctionalization of ulvan scaffolds for bone tissue engineering. ACS applied materials \& interfaces, 2014. 6(5): p. 3211-3218.

123. Gupta, S. and N. Abu-Ghannam, Bioactive potential and possible health effects of edible brown seaweeds. Trends in Food Science \& Technology, 2011. 22(6): p. 315-326.

124. Mestechkina, N. and V. Shcherbukhin, Sulfated polysaccharides and their anticoagulant activity: A review. Applied Biochemistry and Microbiology, 2010. 46(3): p. 267-273.

125. Jiao, G., G. Yu, J. Zhang, and H. Ewart, Chemical structures and bioactivities of sulfated polysaccharides from marine algae. Marine drugs, 2011. 9(2): p. 196-223.

126. Katti, D.S., R. Vasita, and K. Shanmugam, Improved biomaterials for tissue engineering applications: surface modification of polymers. Current topics in medicinal chemistry, 2008. 8(4): p. 341-353.

127. Kong, X., J. Wang, L. Cao, Y. Yu, and C. Liu, Enhanced osteogenesis of bone morphology protein-2 in 2-N, 6-O-sulfated chitosan immobilized PLGA scaffolds. Colloids and Surfaces B: Biointerfaces, 2014. 122: p. 359-367.

128. Paluck, S.J., T.H. Nguyen, and H.D. Maynard, Heparin-mimicking polymers: synthesis and biological applications. Biomacromolecules, 2016. 17(11): p. 3417-3440.

129. Gerecht, S., J.A. Burdick, L.S. Ferreira, S.A. Townsend, R. Langer, and G. Vunjak-Novakovic, Hyaluronic acid hydrogel for controlled self-renewal and differentiation of human embryonic stem cells. Proceedings of the National Academy of Sciences, 2007. 104(27): p. 11298-11303.

130. Burdick, J.A. and G.D. Prestwich, Hyaluronic acid hydrogels for biomedical applications. Advanced materials, 2011. 23(12).

131. Camci-Unal, G., D. Cuttica, N. Annabi, D. Demarchi, and A. Khademhosseini, Synthesis and characterization of hybrid hyaluronic acid-gelatin hydrogels. Biomacromolecules, 2013. 14(4): p. 1085-1092.

132. Xu, X., A.K. Jha, R.L. Duncan, and X. Jia, Heparin-decorated, hyaluronic acid-based hydrogel particles for the controlled release of bone morphogenetic protein 2. Acta biomaterialia, 2011. 7(8): p. 3050-3059. 
133. Jha, A.K., W. Yang, C.B. Kirn-Safran, M.C. Farach-Carson, and X. Jia, Perlecan domain Iconjugated, hyaluronic acid-based hydrogel particles for enhanced chondrogenic differentiation via BMP-2 release. Biomaterials, 2009. 30(36): p. 6964-6975.

134. Srinivasan, P.P., S.Y. McCoy, A.K. Jha, W. Yang, X. Jia, M.C. Farach-Carson, and C.B. KirnSafran, Injectable perlecan domain 1-hyaluronan microgels potentiate the cartilage repair effect of BMP2 in a murine model of early osteoarthritis. Biomedical Materials, 2012. 7(2): p. 024109.

135. Bhakta, G., B. Rai, Z.X. Lim, J.H. Hui, G.S. Stein, A.J. van Wijnen, V. Nurcombe, G.D. Prestwich, and S.M. Cool, Hyaluronic acid-based hydrogels functionalized with heparin that support controlled release of bioactive BMP-2. Biomaterials, 2012. 33(26): p. 6113-6122.

136. Hintze, V., A. Miron, S. Moeller, M. Schnabelrauch, H.-P. Wiesmann, H. Worch, and D. Scharnweber, Sulfated hyaluronan and chondroitin sulfate derivatives interact differently with human transforming growth factor-61 (TGF-61). Acta biomaterialia, 2012. 8(6): p. 21442152.

137. Lyon, M., G. Rushton, and J.T. Gallagher, The interaction of the transforming growth factorBs with heparin/heparan sulfate is isoform-specific. Journal of Biological Chemistry, 1997. 272(29): p. 18000-18006.

138. Verlee, A., S. Mincke, and C.V. Stevens, Recent developments in antibacterial and antifungal chitosan and its derivatives. Carbohydrate polymers, 2017. 164: p. 268-283.

139. Mao, J.S., Y.L. Cui, X.H. Wang, Y. Sun, Y.J. Yin, H.M. Zhao, and K. De Yao, A preliminary study on chitosan and gelatin polyelectrolyte complex cytocompatibility by cell cycle and apoptosis analysis. Biomaterials, 2004. 25(18): p. 3973-3981.

140. Cao, L., J.A. Werkmeister, J. Wang, V. Glattauer, K.M. McLean, and C. Liu, Bone regeneration using photocrosslinked hydrogel incorporating rhBMP-2 loaded 2-N, 6-O-sulfated chitosan nanoparticles. Biomaterials, 2014. 35(9): p. 2730-2742.

141. Cao, L., J. Wang, J. Hou, W. Xing, and C. Liu, Vascularization and bone regeneration in a critical sized defect using 2-N, 6-O-sulfated chitosan nanoparticles incorporating BMP-2. Biomaterials, 2014. 35(2): p. 684-698.

142. Pan, Y., J. Chen, Y. Yu, K. Dai, J. Wang, and C. Liu, Enhancement of BMP-2-mediated angiogenesis and osteogenesis by 2-N, 6-O-sulfated chitosan in bone regeneration. Biomaterials science, 2018. 6(2): p. 431-439.

143. Lord, M.S., B.M. Tsoi, B.L. Farrugia, S.S. Ting, S. Baker, W.P. Wiesmann, and J.M. Whitelock, Synthesis and characterization of water soluble biomimetic chitosans for bone and cartilage tissue regeneration. Journal of Materials Chemistry B, 2014. 2(38): p. 6517-6526.

144. Farrugia, B.L., Y. Mi, H.N. Kim, J.M. Whitelock, S.M. Baker, W.P. Wiesmann, Z. Li, P. Maitz, and M.S. Lord, Chitosan-Based Heparan Sulfate Mimetics Promote Epidermal Formation in a Human Organotypic Skin Model. Advanced Functional Materials, 2018. 28(36): p. 1802818.

145. LogithKumar, R., A. KeshavNarayan, S. Dhivya, A. Chawla, S. Saravanan, and N. Selvamurugan, $A$ review of chitosan and its derivatives in bone tissue engineering. Carbohydrate polymers, 2016. 151: p. 172-188.

146. Kim, I.-Y., S.-J. Seo, H.-S. Moon, M.-K. Yoo, I.-Y. Park, B.-C. Kim, and C.-S. Cho, Chitosan and its derivatives for tissue engineering applications. Biotechnology advances, 2008. 26(1): p. 121.

147. Boateng, J.S., K.H. Matthews, H.N. Stevens, and G.M. Eccleston, Wound healing dressings and drug delivery systems: a review. Journal of pharmaceutical sciences, 2008. 97(8): p. 2892-2923.

148. Kogelenberg, S.v., Z. Yue, J.N. Dinoro, C.S. Baker, and G.G. Wallace, Three-Dimensional Printing and Cell Therapy for Wound Repair. Advances in wound care, 2018. 7(5): p. 145-156.

149. Tønnesen, H.H. and J. Karlsen, Alginate in drug delivery systems. Drug development and industrial pharmacy, 2002. 28(6): p. 621-630. 
150. Jia, J., D.J. Richards, S. Pollard, Y. Tan, J. Rodriguez, R.P. Visconti, T.C. Trusk, M.J. Yost, H. Yao, and R.R. Markwald, Engineering alginate as bioink for bioprinting. Acta biomaterialia, 2014. 10(10): p. 4323-4331.

151. Freeman, F.E. and D.J. Kelly, Tuning alginate bioink stiffness and composition for controlled growth factor delivery and to spatially direct MSC fate within bioprinted tissues. Scientific reports, 2017. 7(1): p. 17042.

152. Di Giuseppe, M., N. Law, B. Webb, R.A. Macrae, L.J. Liew, T.B. Sercombe, R.J. Dilley, and B.J. Doyle, Mechanical behaviour of alginate-gelatin hydrogels for 3D bioprinting. Journal of the mechanical behavior of biomedical materials, 2018. 79: p. 150-157.

153. Lee, K.Y. and D.J. Mooney, Alginate: properties and biomedical applications. Progress in polymer science, 2012. 37(1): p. 106-126.

154. Evangelista, M.B., S.X. Hsiong, R. Fernandes, P. Sampaio, H.J. Kong, C.C. Barrias, R. Salema, M.A. Barbosa, D.J. Mooney, and P.L. Granja, Upregulation of bone cell differentiation through immobilization within a synthetic extracellular matrix. Biomaterials, 2007. 28(25): p. 3644-55.

155. Degala, S., W.R. Zipfel, and L.J. Bonassar, Chondrocyte calcium signaling in response to fluid flow is regulated by matrix adhesion in 3-D alginate scaffolds. Arch Biochem Biophys, 2011. 505(1): p. 112-7.

156. Bidarra, S.J., C.C. Barrias, M.A. Barbosa, R. Soares, and P.L. Granja, Immobilization of human mesenchymal stem cells within RGD-grafted alginate microspheres and assessment of their angiogenic potential. Biomacromolecules, 2010. 11(8): p. 1956-1964.

157. Kasai, Y., A. Akahira, S. Kakuta, A. Abudula, K. Urayama, and T. Takigawa, Preparation and electrochemical properties of alginate sulfate electrolyte membranes. 2008.

158. Freeman, I., A. Kedem, and S. Cohen, The effect of sulfation of alginate hydrogels on the specific binding and controlled release of heparin-binding proteins. Biomaterials, 2008. 29(22): p. 3260-3268.

159. Arlov, $\varnothing$. and G. Skjåk-Bræk, Sulfated Alginates as Heparin Analogues: A Review of Chemical and Functional Properties. Molecules, 2017. 22(5): p. 778.

160. Mhanna, R., A. Kashyap, G. Palazzolo, Q. Vallmajo-Martin, J. Becher, S. Möller, M. Schnabelrauch, and M. Zenobi-Wong, Chondrocyte culture in three dimensional alginate sulfate hydrogels promotes proliferation while maintaining expression of chondrogenic markers. Tissue Engineering Part A, 2014. 20(9-10): p. 1454-1464.

161. Benya, P.D. and J.D. Shaffer, Dedifferentiated chondrocytes reexpress the differentiated collagen phenotype when cultured in agarose gels. Cell, 1982. 30(1): p. 215-224.

162. Bonaventure, J., N. Kadhom, L. Cohen-Solal, K. Ng, J. Bourguignon, C. Lasselin, and P. Freisinger, Reexpression of cartilage-specific genes by dedifferentiated human articular chondrocytes cultured in alginate beads. Experimental cell research, 1994. 212(1): p. 97-104.

163. Hauselmann, H.J., K. Masuda, E.B. Hunziker, M. Neidhart, S. Mok, B.A. Michel, and E. Thonar, Adult human chondrocytes cultured in alginate form a matrix similar to native human articular cartilage. American Journal of Physiology-Cell Physiology, 1996. 271(3): p. C742C752.

164. Wang, G., A. Woods, S. Sabari, L. Pagnotta, L.-A. Stanton, and F. Beier, RhoA/ROCK signaling suppresses hypertrophic chondrocyte differentiation. Journal of Biological Chemistry, 2004. 279(13): p. 13205-13214.

165. Bruschi, M.L., F.B. Borghi-Pangoni, M.V. Junqueira, and S.B. de Souza Ferreira, Nanostructured therapeutic systems with bioadhesive and thermoresponsive properties, in Nanostructures for Novel Therapy. 2017, Elsevier. p. 313-342.

166. Nishiyama, Y., P. Langan, and H. Chanzy, Crystal structure and hydrogen-bonding system in cellulose I $\mathrm{B}$ from synchrotron $X$-ray and neutron fiber diffraction. Journal of the American Chemical Society, 2002. 124(31): p. 9074-9082. 
167. Edgar, K.J., C.M. Buchanan, J.S. Debenham, P.A. Rundquist, B.D. Seiler, M.C. Shelton, and D. Tindall, Advances in cellulose ester performance and application. Progress in Polymer Science, 2001. 26(9): p. 1605-1688.

168. Schweiger, R.G., Polysaccharide sulfates. I. Cellulose sulfate with a high degree of substitution. Carbohydrate Research, 1972. 21(2): p. 219-228.

169. Anderson, R.A., K.A. Feathergill, X.H. Diao, M.D. Cooper, R. Kirkpatrick, B.C. Herold, G.F. Doncel, C.J. Chany, D.P. Waller, W.F. Rencher, and L.J. Zaneveld, Preclinical evaluation of sodium cellulose sulfate (Ushercell) as a contraceptive antimicrobial agent. J Androl, 2002. 23(3): p. 426-38.

170. Huang, G.P., A. Molina, N. Tran, G. Collins, and T.L. Arinzeh, Investigating cellulose derived glycosaminoglycan mimetic scaffolds for cartilage tissue engineering applications. Journal of tissue engineering and regenerative medicine, 2018. 12(1).

171. Vinardell, T., R.A. Rolfe, C.T. Buckley, E.G. Meyer, M. Ahearne, P. Murphy, and D.J. Kelly, Hydrostatic pressure acts to stabilise a chondrogenic phenotype in porcine joint tissue derived stem cells. Eur Cell Mater, 2012. 23(23): p. 121-132.

172. Portocarrero Huang, G., R. Menezes, R. Vincent, W. Hammond, L. Rizio, G. Collins, and T.L. Arinzeh, Gelatin Scaffolds Containing Partially Sulfated Cellulose Promote Mesenchymal Stem Cell Chondrogenesis. Tissue Engineering Part A, 2017. 23(17-18): p. 1011-1021.

173. Pulkkinen, H., V. Tiitu, E. Lammentausta, E.-R. Hämäläinen, I. Kiviranta, and M.J. Lammi, Cellulose sponge as a scaffold for cartilage tissue engineering. Bio-medical materials and engineering, 2006. 16(4): p. S29-S35.

174. Thongsomboon, W., D.O. Serra, A. Possling, C. Hadjineophytou, R. Hengge, and L. Cegelski, Phosphoethanolamine cellulose: A naturally produced chemically modified cellulose. Science, 2018. 359(6373): p. 334-338.

175. Odén, A., E.V. McCloskey, J.A. Kanis, N.C. Harvey, and H. Johansson, Burden of high fracture probability worldwide: secular increases 2010-2040. Osteoporosis International, 2015. 26(9): p. 2243-2248.

176. Amroodi, M.N., V. Behshad, and P. Motaghi, Long-term Results, Functional Outcomes and Complications after Open Reduction and Internal Fixation of Neglected and Displaced Greater Tuberosity of Humerus Fractures. Archives of Bone and Joint Surgery, 2016. 4(4): p. 330.

177. Wang, W. and K.W. Yeung, Bone grafts and biomaterials substitutes for bone defect repair: A review. Bioactive materials, 2017.

178. Bauman, R.D., D.G. Lewallen, and A.D. Hanssen, Limitations of structural allograft in revision total knee arthroplasty. Clinical orthopaedics and related research, 2009. 467(3): p. 818-824.

179. Bose, S., M. Roy, and A. Bandyopadhyay, Recent advances in bone tissue engineering scaffolds. Trends in biotechnology, 2012. 30(10): p. 546-554.

180. Athanasiou, V.T., D.J. Papachristou, A. Panagopoulos, A. Saridis, C.D. Scopa, and P. Megas, Histological comparison of autograft, allograft-DBM, xenograft, and synthetic grafts in a trabecular bone defect: an experimental study in rabbits. Medical Science Monitor, 2009. 16(1): p. BR24-BR31.

181. Kim, H.D., E.A. Lee, Y.-H. An, S.L. Kim, S.S. Lee, S.J. Yu, H.L. Jang, K.T. Nam, S.G. Im, and N.S. Hwang, Chondroitin sulfate-based biomineralizing surface Hydrogels for bone tissue engineering. ACS applied materials \& interfaces, 2017. 9(26): p. 21639-21650.

182. Dong, W., Y. Xiao, Y. Piao, and Y. Chen, In vivo tissue engineering: A new concept. Di 1 jun yi da xue xue bao= Academic journal of the first medical college of PLA, 2004. 24(9): p. 969974.

183. Yang, H.S., W.-G. La, S.H. Bhang, J.-Y. Jeon, J.H. Lee, and B.-S. Kim, Heparin-conjugated fibrin as an injectable system for sustained delivery of bone morphogenetic protein-2. Tissue Engineering Part A, 2010. 16(4): p. 1225-1233. 
184. Wang, X., J.D. Mabrey, and C. Agrawal, An interspecies comparison of bone fracture properties. Bio-medical materials and engineering, 1998. 8(1): p. 1-9.

185. Prodinger, P.M., R. Burgkart, K. Kreutzer, F. Liska, H. Pilge, A. Schmitt, M. Knödler, B.M. Holzapfel, A. Hapfelmeier, and T. Tischer, Does anticoagulant medication alter fracturehealing? A morphological and biomechanical evaluation of the possible effects of rivaroxaban and enoxaparin using a rat closed fracture model. PloS one, 2016. 11(7): p. e0159669.

186. Zhao, D., S. Yu, B. Sun, S. Gao, S. Guo, and K. Zhao, Biomedical Applications of Chitosan and Its Derivative Nanoparticles. Polymers, 2018. 10(4): p. 462.

187. Zhou, H., J. Qian, J. Wang, W. Yao, C. Liu, J. Chen, and X. Cao, Enhanced bioactivity of bone morphogenetic protein-2 with low dose of 2-N, 6-O-sulfated chitosan in vitro and in vivo. Biomaterials, 2009. 30(9): p. 1715-1724.

188. Bai, X., S. Lü, Z. Cao, B. Ni, X. Wang, P. Ning, D. Ma, H. Wei, and M. Liu, Dual crosslinked chondroitin sulfate injectable hydrogel formed via continuous Diels-Alder (DA) click chemistry for bone repair. Carbohydrate polymers, 2017. 166: p. 123-130.

189. Lü, S., X. Bai, H. Liu, P. Ning, Z. Wang, C. Gao, B. Ni, and M. Liu, An injectable and self-healing hydrogel with covalent cross-linking in vivo for cranial bone repair. Journal of Materials Chemistry B, 2017. 5(20): p. 3739-3748.

190. Park, H., X. Guo, J.S. Temenoff, Y. Tabata, A.I. Caplan, F.K. Kasper, and A.G. Mikos, Effect of swelling ratio of injectable hydrogel composites on chondrogenic differentiation of encapsulated rabbit marrow mesenchymal stem cells in vitro. Biomacromolecules, 2009. 10(3): p. 541-546.

191. de Misquita, M.R.D.O.F., R. Bentini, and F. Goncalves, The performance of bone tissue engineering scaffolds in in vivo animal models: A systematic review. Journal of biomaterials applications, 2016. 31(5): p. 625-636.

192. Lyu, S.-R., C.-C. Hsu, and C.-W. Lin, Arthroscopic cartilage regeneration facilitating procedure for osteoarthritic knee. BMC musculoskeletal disorders, 2012. 13(1): p. 226.

193. Steadman, J.R., W.G. Rodkey, and J.J. Rodrigo, Microfracture: surgical technique and rehabilitation to treat chondral defects. Clinical Orthopaedics and Related Research ${ }^{\circledR}, 2001$. 391: p. S362-S369.

194. Roberts, S., J. Menage, L. Sandell, E. Evans, and J. Richardson, Immunohistochemical study of collagen types I and II and procollagen IIA in human cartilage repair tissue following autologous chondrocyte implantation. The Knee, 2009. 16(5): p. 398-404.

195. Felson, D.T., R.C. Lawrence, P.A. Dieppe, R. Hirsch, C.G. Helmick, J.M. Jordan, R.S. Kington, N.E. Lane, M.C. Nevitt, and Y. Zhang, Osteoarthritis: new insights. Part 1: the disease and its risk factors. Annals of internal medicine, 2000. 133(8): p. 635-646.

196. Jiang, X., J. Liu, Q. Liu, Z. Lu, L. Zheng, J. Zhao, and X. Zhang, Therapy for cartilage defects: functional ectopic cartilage constructed by cartilage-simulating collagen, chondroitin sulfate and hyaluronic acid ( $\mathrm{CCH}$ ) hybrid hydrogel with allogeneic chondrocytes. Biomaterials science, 2018. 6(6): p. 1616-1626.

197. Han, L., M. Wang, P. Li, D. Gan, L. Yan, J. Xu, K. Wang, L. Fang, C.W. Chan, and H. Zhang, Mussel-inspired tissue adhesive hydrogel based on polydopamine-chondroitin sulfate complex for growth-factor-free cartilage regeneration. ACS applied materials \& interfaces, 2018.

198. Berthiaume, F., T.J. Maguire, and M.L. Yarmush, Tissue engineering and regenerative medicine: history, progress, and challenges. Annual review of chemical and biomolecular engineering, 2011. 2: p. 403-430.

199. Popa, E.G., R.L. Reis, and M.E. Gomes, Seaweed polysaccharide-based hydrogels used for the regeneration of articular cartilage. Critical reviews in biotechnology, 2015. 35(3): p. 410-424. 
200. Sherman, S.L., J. Garrity, K. Bauer, J. Cook, J. Stannard, and W. Bugbee, Fresh osteochondral allograft transplantation for the knee: current concepts. J Am Acad Orthop Surg, 2014. 22(2): p. 121-33.

201. Zhou, F., X. Zhang, D. Cai, J. Li, Q. Mu, W. Zhang, S. Zhu, Y. Jiang, W. Shen, and S. Zhang, Silk fibroin-chondroitin sulfate scaffold with immuno-inhibition property for articular cartilage repair. Acta biomaterialia, 2017. 63: p. 64-75.

202. Liao, J., Y. Qu, B. Chu, X. Zhang, and Z. Qian, Biodegradable CSMA/PECA/graphene porous hybrid scaffold for cartilage tissue engineering. Scientific reports, 2015. 5: p. 9879.

203. Im, G.I. and J.H. Lee, Repair of osteochondral defects with adipose stem cells and a dual growth factor-releasing scaffold in rabbits. Journal of Biomedical Materials Research Part B: Applied Biomaterials: An Official Journal of The Society for Biomaterials, The Japanese Society for Biomaterials, and The Australian Society for Biomaterials and the Korean Society for Biomaterials, 2010. 92(2): p. 552-560.

204. Re'em, T., F. Witte, E. Willbold, E. Ruvinov, and S. Cohen, Simultaneous regeneration of articular cartilage and subchondral bone induced by spatially presented TGF-beta and BMP-4 in a bilayer affinity binding system. Acta biomaterialia, 2012. 8(9): p. 3283-3293.

\section{Figures}

\section{Figure captions}

Figure 1: A schematic showing the core-principles behind tissue engineering.

Figure 2: Some of the most important sulfated polysaccharides reviewed herein have been highlighted in this figure along with their derivation source and chemical structure.

\section{Figure 3: The growth factor retention capacity of heparin. (a) Schematic showing the} design principle behind the biphasic silk fibroin scaffold used in the study. (b) The heparin loading efficiency and its release profile from the scaffold in displayed here. (c) The sustained release of TGF- $\beta 2$ and GDF5 is displayed here. Crosslinked heparin significantly delayed the growth factor release. Modified from[77], with permission from Elsevier, Copyright 2018.

\section{Figure 4: The growth factor retention capacity of sulfated chitosan. (a) Schematic} showing the design principle behind the S-NP incorporated gelatin scaffolds. (b) The size distribution and scanning electron microscopy images (SEM) of the S-NP's are displayed here. (c) The sustained release of BMP-2 from the scaffolds employed in this study is displayed here. Modified from[141], with permission from Elsevier, Copyright 2014. 
1 Figure 5: A schematic showing the growth factor bind properties of sulfated alginates and

2 their ability to promote chrondogenesis through important signalling pathways. Modified from [159], with permission from MDPI, Copyright 2017.

Figure 6: A chondroitin (CS)-based scaffold for bone tissue engineering. (a) The manufacturing of the PEGDA-MeCS hydrogel and its hydroxyapatite (HAP) formation capacity is shown here. (b) The calcification and HAP formation of the cell-laden hydrogels after 21 days are shown here through photographic images of the hydrogels at relevant time points. (c) The bone regenerative capacity of the respective scaffolds incorporating different concentrations of CS was quantified through Micro-CT analysis after 8 weeks of implantation. (d) The bone area (BS/TS) and bone volume (BV/TV) were also calculated and are displayed here. Adapted with permission from [181]. Copyright (2017), American Chemical Society.

Figure 7: A tissue adhesive CS-based scaffold for cartilage tissue engineering. (a) The CS-based scaffold was made tissue adhesive by polymerizing dopamine (DA) and acrylamide (AM) into it. (b) The tissue adhesive properties of the scaffold was mediated by the many amino groups present on PDA and PAM. (c) The adhesion strength of the various manufactured scaffolds towards porcine skin is shown here. (d) The cartilage regenerative potential was highest for the PDA-CS-PAM hydrogel. (e) This was further validated by analysing the Modified O' driscoll scoring for the implanted scaffolds after 3 months of implantation. Adapted with permission from [197]. Copyright (2018). American Chemical Society.

Figure 8: A Silk-CS-based scaffold for osteochondral tissue engineering. (a) The manufacturing process behind the Silk-CS scaffold is shown here. (b) The chrondrogenic and anti-inflammatory capacity of the Silk-CS was quantified from expression of relevant gene markers. (c) Histological evaluation of the scaffolds after 12 weeks of implantation. H\&E is short for hematoxyling and eosin and SO for Safranin O. (D) The histological scores for subchondral bone formation was evaluated after 6 and 12 weeks. Modified from [201], with permission from Elsevier, Copyright 2017.

\section{Figure 9: A sulfated hyaluronic acid scaffold for osteochondral tissue engineering. (a)} The manufacturing scheme behind the scaffolds are shown here, where LS-MeHA and HS- 
$1 \mathrm{MeHa}$ are short for low sulfated and high sulfated methacrylated hyaluronic acid (HA), 2 respectively. (b) The TGF- $\beta 1$ retention capacity of the various scaffolds employed in the study 3 is shown here. (C) Histological staining of the respective hMSCs-laden scaffolds after 42 days 4 of implantation. Modified from [52], with permission from Elsevier, Copyright 2017. 